\title{
Hiring, Firing, and Relocation under Employment Protection*
}

\author{
Min Dai ${ }^{\dagger}$ \\ Department of Mathematics \\ National University of Singapore
}

\author{
Jussi Keppo ${ }^{\ddagger}$ \\ Business School \\ National University of Singapore
}

\author{
Tim Maull ${ }^{\S}$ \\ IOE Department \\ University of Michigan
}

April 2, 2015

\begin{abstract}
We analyze how hiring and firing costs as well as firing regulatory delays affect firms' hiring, firing, and relocation policy with a stochastic control model. These frictions are substantial; e.g., the firing delay can be almost a year. In the model hiring and firing costs depend on the firm size and the number of people hired or fired. Based on our simulations, hiring and firing elasticities without relocation are highest with respect to demand and productivity volatility and the hiring and firing variable costs. The elasticity of firing due to relocation is highest with respect to the firm-sized firing cost.
\end{abstract}

\footnotetext{
${ }^{*}$ We have benefited from the discussions with Sumit Agarwal, Martin Bodenstein, Davin Chor, Feryal Erhun, Lones Smith, Pauli Murto, Samu Peura, and the participants at the Integrated Risk Management in Operations and Global Supply Chain Management Conference, INFORMS Conference, INFORMS Applied Probability Society Conference, seminars in NUS, HKUST, and University of Michigan. We are also grateful to Jingwei Xu for research assistance. This material is based upon work supported by the National Science Foundation under grant number 0114368, National University of Singapore under grant number R314000097133, and by Singapore Academic Research Fund under grant number R-146-000-188/201-112. Any opinions, findings, and conclusions or recommendations expressed in this material are those of the authors and do not necessarily reflect the views of the National Science Foundation, National University of Singapore, and Singapore Academic Research Fund.

†email: matdmenus.edu.sg

†email: keppo@nus.edu.sg

§email: timmaull@umich.edu
} 


\section{Introduction}

Governments pass employment regulations with the aim of keeping people employed. However, the employment protection legislation is risky in a sense that it might have unintended consequences; due to the employment protection, companies might have lower incentive to hire new workers and higher incentive to relocate its operations to other states or countries. For instance, the employment protection legislation is frequently pointed out when comparing the 'Anglo-Saxon' economies of the United States and the United Kingdom which have low levels of employment protection and low unemployment rates with the continental European economies of France, Germany, Italy and Belgium which have high levels of labor protection and nearly twice as high unemployment rates. ${ }^{1}$ In this paper, we study the effects of hiring and firing costs as well as firing regulatory delays on firms' hiring, firing, and relocation policies. Specifically, we study which kind of firms are most affected by the labor market frictions and how much, and when do these firms relocate to other countries or states.

Firms need to respond to changes in consumer demand. One way to do this is to change the number of workers in the firm and this way the output. However, hiring and firing workers do not happen instantly and without costs. There are substantial hiring and training costs for new workers, and severance and layoff costs for firing workers. Additionally, union contracts, regulatory constraints and processes create a delay from few days to almost a year when firms decide to fire workers. The length of the delay depends on the country, time employed in the job, if the firing is individual or collective, and if the worker is permanent employee or temporary. As an example, Figure 1 shows the minimum regulatory delay length for various OECD countries in 2004. In this paper, we model a firm's optimal workforce decisions in response to changing consumer demand for its product and uncertainty in the workers' productivity under costs and delays in changing its workforce. Further, we analyze how an option to relocate the firm's operations affects the hiring and firing policy under different hiring and firing frictions. To do this we use a stochastic control model where the objective is to maximize the present value of the firm's expected cash flows. In this framework the labor level is a risk management decision; workers have a holding cost but they hedge against future demand and productivity uncertainties. For instance, the firm

\footnotetext{
${ }^{1}$ See e.g. Siebert (1997); Tiplady, Rachel 'Job Security Ignites Debate in France', BloombergBusinessweek, March 20, 2006; Brat, Ilan and Zampano, Giada, 'In Europe, Job Protections for Older Generation Are Barriers for Younger Workers', Wall Street Journal, June 25, 2014.
} 
may hold fewer workers to hedge against downturns in demand, especially when it is costly and time-consuming to layoff workers.

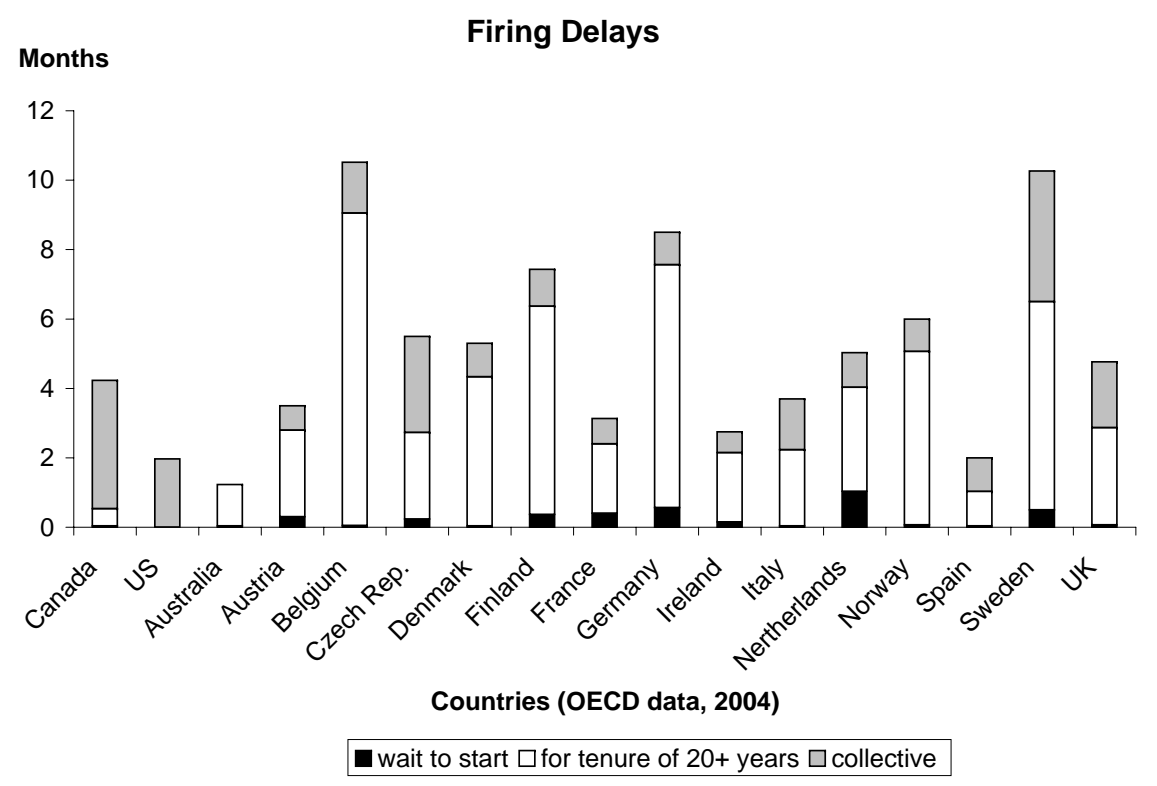

Figure 1: Delay length for three types of dismissals in various OECD countries (OECD 2004).

We first derive Hamilton-Jacobi-Bellman (HJB) equation for the value of the firm under hiring and firing costs and a firing delay, and then we solve the equation numerically. ${ }^{2}$ Since the length of the firing delay is substantial in some countries, it is important to include the delay in the HJB equation. Delays have been modeled in other contexts such as bank recapitalization (e.g. Peura and Keppo 2006), power generation (e.g. Blankenship and Menaldi 1984), real options (e.g. Alvarez and Keppo 2002), and in a theoretical stochastic control framework (e.g. Robin 1977). We utilize these models in the HJB equation; however, our model is more complicated (e.g. two impulse controls) and, thus, these papers cannot be applied directly to our problem. We also introduce "firm-sized" hiring and firing costs that are proportional to the number of employees. This cost is motivated by some regulations that apply only for large companies (e.g. Table 2.A.9 in OECD, 1999). For instance, the definition of collective dismissal, which triggers various

\footnotetext{
${ }^{2}$ We solve the model numerically since the firm value cannot be solved analytically due to the firing delay and fixed costs. However, we derive some analytical comparative statics.
} 
regulations, depends on the size of the firm and the number of fired workers in several OECD countries. We show that the firm-sized costs postpone hiring and firing but raise the hiring and firing quantities, especially for large companies. This is consistent with Davis et al. (2006) who report lumpy labor adjustments with about two-thirds of job creation and destruction occurring at places where labor changes by more than $10 \%$ per quarter.

By a realistic range of parameter estimates calculated from Bloom (2009), we simulate the optimal hiring, firing, and relocation policy and estimate hiring and firing elasticities. The firing delay lowers the profitability and changes substantially the hiring and firing policy of companies that have high demand or productivity uncertainty. ${ }^{3}$ When the uncertainty is high, firing falls in the delay because the delay raises uncertainty in the firing value; hiring also falls because firing is more difficult and this decreases the value of employees. For instance, when the demand and productivity volatility is twice our baseline case then doubling the firing delay decreases hiring by $6 \%$ and firing by $10 \%$. We find even stronger effects with the hiring and firing costs. In our model the hiring and firing costs depend on the firm size and the number of people hired or fired. Based on our simulations, hiring and firing elasticities without relocation are highest with respect to the demand and productivity volatility and to the proportional hiring and firing costs because high uncertainty companies need to adjust their labor level substantially and the proportional costs penalize every employee hired or fired. The elasticity of firing due to relocation is highest with respect to the firm-sized firing cost because the firm-sized firing cost is paid every firing time and, if the cost is high, companies prefer to pay this only once, i.e., they relocate sooner. Further, hiring and firing policies of companies that have option to relocate are more sensitive to labor market frictions than of those without the option because when hiring and firing frictions rise, the companies wait for optimal relocation time and, therefore, they decrease hiring and firing substantially. The value of the relocation option is substantial; for instance, when the firing delay is one year and the demand and productivity uncertainty is twice our baseline case then the relocation option raises the firm value by about $9 \%$. Thus, the high uncertainty companies have high incentive to relocate to countries or states with lower labor market frictions. Example is a high-tech firm that faces a long firing delay, high uncertainty on productivity of

\footnotetext{
${ }^{3}$ As in Cunat and Melitz (2012), our model indicates that due to the lower profitability the fraction of companies with high demand or productivity uncertainty is lower in countries and states with high labor market frictions.
} 
its employees, and a high search cost for new hires. ${ }^{4}$ The relocation reduces the fraction of companies with high demand or productivity uncertainty in the countries and states with high labor market frictions. This raises the prevalence of low uncertainty firms and decreases job reallocation rates in these countries and states since low uncertainty firms hire and fire less. This is consistent with Haltiwanger et al. (2014) who find empirically that stringent hiring and firing regulations reduce the pace of job reallocation. Our model is also consistent with Davis et al. (2007, 2010) and Decker et al. (2014) who show that the volatility of business growth and job reallocation rates have fallen substantially in US since 1980. By Davis and Haltiwanger (2014), the decrease in the job reallocation rates is negative for the economy since falling labor market fluidity raises unemployment rates, especially among marginal workers and those with limited skills.

Estimation of the relationship between labor market frictions and employment is difficult. Many studies use multivariate regressions of policy parameters on employment levels over various countries (e.g., Nickell 1997). However, there are many observed and unobserved variables that should be controlled and there are also several endogeneity issues. Therefore, the academic literature of the effect of employment protection legislation on unemployment is not clear and studies often lead to opposing results. For example, Siebert (1997) argues that the inflexibility of labor markets in Europe is the reason for the high unemployment. On the other hand, Nickell (1997) shows that some labor market rigidities do not cause unemployment and argues that it is important to find out what regulations prolong unemployment. ${ }^{5}$ Further, Bertola and Rogerson (1997) and Hopenhayn and Rogerson (1993) have opposite predictions as to the net employment effects of firing costs. Bentolila and Saint-Paul (1994) show that proportional hiring and firing costs have a positive and negative effect on average steady-state employment level depending on the magnitude of the costs. Bertola (1992) models a firm in a deterministic continuous time framework and shows that the effect of hiring and firing costs on employment level depends on the size of the costs, and the interest rate and attrition rates. Bentolila and Bertola (1990) model a

\footnotetext{
${ }^{4}$ This could be one reason why the high-tech industry share of total manufacturing output is lower in Europe than in US, see Rausch, Lawrence, 'High-Tech Industries Drive Global Economic Activity', NSF, July 20, 1998, available at http: / /www.nsf.gov/statistics/issuebrf/sib98319.htm and Gordon, Sarah, 'Europe loses ground in global high-tech race', Financial Times, February 20, 2014.

${ }^{5}$ Related to this, Krause and Uhlig (2011), Faia (2008), and Faia et al. (2013) study fiscal and monetary policies and show that the monetary policy rule should respond to unemployment alongside with inflation and that demand stimuli have less impact on job creation and employment than hiring subsidies and short-time work.
} 
firm in a continuous time stochastic demand framework with proportional hiring and firing costs, and we utilize their framework. We contribute to the modeling of firm behavior by incorporating firing delays, firm-sized costs, and relocation option. Chen et al. (2003) considers macroeconomic shocks in addition to random demand for the firm. Acemoglu and Hawkins (2014), Bloom (2009), Davis et al. (2010), Ljungqvist and Sargent (1995, 2008), and Lubik (2012) show that uncertainty shocks drive aggregate output and employment, and that the shocks can cause persistent changes in unemployment.

The rest of the paper is organized as follows. We present the model setup without relocation option in Section 2 and then in Section 3 we show the comparative statics of the model. Section 4 extends the model to include the relocation option and the comparative statics of the extended model are in Section 5 . Finally Section 6 concludes.

\section{Model without relocation option}

As in Bentolila and Bertola (1990), we consider a firm that faces a random demand for its product. The firm can only control its labor level $L_{t}$. It has a linear production technology that uses homogeneous labor as a factor of production. This firm faces a constant-elasticity demand function which is given by

$$
Q_{t}=\tilde{Z}_{t} P_{t}^{\frac{1}{\lambda-1}}
$$

where $P_{t}$ and $Q_{t}$ are the price and quantity sold by the firm at time $t$. The firm has market power in the price that it can charge for its product, and this market power is measured by $\lambda$ which is the inverse of the markup factor. However, the firm's output is limited by the productivity of its workforce, $A_{t}$, and the number of workers, $L_{t}$, at a given time $t: Q_{t} \leq A_{t} L_{t}$, where $A_{t}=A a_{t}$ and

$$
d a_{t}=\mu_{a} a_{t} d t+\sigma_{a} a_{t} d W_{t}^{a}
$$

where the parameters $\mu_{a}$ and $\sigma_{a}$ are positive, and $\left\{W_{t}^{a}: t \geq 0\right\}$ is a standard Wiener process ${ }^{6}$. Thus, the productivity follows a geometric Brownian motion process and, therefore, we have

\footnotetext{
${ }^{6}$ This Wiener process is on a probability space $(\Omega, F, P)$ along with the standard filtration $\left\{\mathcal{F}_{t}: t \geq 0\right\}$. Here $\Omega$ is a set, $\mathcal{F}$ is a $\sigma$-algebra, $P$ is a probability measure on $\mathcal{F}$, and $\left(\mathcal{F}_{t}\right)_{0 \leq t}$ is an increasing family of $\sigma$-algebras.
} 
$A_{t}=A e^{\left(\mu_{a}-\frac{1}{2} \sigma_{a}^{2}\right) t+\sigma_{a} W_{t}^{a}} . \tilde{Z}_{t}$ in $(1)$ is the position on the direct demand curve, and it follows

$$
d \tilde{Z}_{t}=\tilde{\mu} \tilde{Z}_{t} d t+\tilde{\sigma} \tilde{Z}_{t} d \tilde{W}_{t}
$$

where the parameters $\tilde{\mu}$ and $\tilde{\sigma}$ are positive, $\left\{\tilde{W}_{t}: t \geq 0\right\}$ is a standard Wiener process, and $d \tilde{W}_{t} d W_{t}^{a}=\rho d t$. Thus, also the demand follows a geometric Brownian motion process and productivity $A_{t}$ and demand $\tilde{Z}_{t}$ might be correlated. Because the marginal revenue from a constant elasticity demand function is always positive, equation (1) implies that the revenues are given by $Q_{t} P_{t}=\tilde{Z}_{t}^{1-\lambda}\left(A_{t} L_{t}\right)^{\lambda}$ at time $t .{ }^{7}$ Any future cash flows are continuously discounted at rate $r$.

The firm pays a wage, $\omega$, to its workers. Workers leave the company with a constant proportional rate $\delta$ and this corresponds to a situation where $1-e^{-\delta}$ is the fraction of employees quitting in a unit of time. In this case the company does not have to pay for them to leave and they leave instantly.

The company controls the number of employees through hiring and firing. When the company hires new employees it pays a firm-size cost, $C_{H}$, that is proportional to the current labor size and a proportional $\operatorname{cost} c_{H}$ that is proportional to the number of employees hired. Similarly, in the case of firing it faces costs $C_{F}$ and $c_{F}$. The firm-sized costs $C_{H}$ and $C_{F}$ extend the usual stochastic control applications that assume fixed cost and/or cost that is proportional to the change of the state variable ( $c_{H}$ and $c_{F}$ in our model). Note that our firm-sized costs are proportional to the level of the state variable before it is changed (in our paper the labor quantity $L$ ) ${ }^{8}$ This can be thought of as a linear approximation of firm size costs of hiring and/or firing workers. Many labor regulations depend on firm size (e.g. Table 2.A.9 in OECD, 1999). For example, the definition of collective dismissal, which triggers various regulations, depends on the size of the firm and the number fired in several OECD countries. ${ }^{9}$ Costs depending on firm size have also been brought

${ }^{7} \mathrm{By}[1], P_{t}=\left(Q_{t} / \tilde{Z}_{t}\right)^{\lambda-1}$ and, thus, the revenues are given by $Q_{t} P_{t}=\frac{Q_{t}^{\lambda}}{\tilde{Z}^{\lambda-1}}$. Therefore, each time $t$ the company maximizes its revenues minus the wage cost: $\max _{Q_{t} \leq A_{t} L_{t}}\left\{\frac{Q_{t}^{\lambda}}{\tilde{Z}^{\lambda-1}}-\omega L_{t}\right\}$, where $\omega$ is the wage cost and $A_{t} L_{t}$ is the output constraint. This gives that the optimal output equals $A_{t} L_{t}$ and, thus, $Q_{t} P_{t}=\tilde{Z}_{t}^{1-\lambda}\left(A_{t} L_{t}\right)^{\lambda}$.

${ }^{8}$ Application of these costs include labor market regulations based on the number of employees (as in our paper), search cost of a specific item in a large inventory, banking regulation that applies to big banks, price impact of a large buy or sell order, capital levies and wealth taxes.

${ }^{9}$ These countries are Austria, Belgium, Denmark, Finland, Germany, Greece, Korea, Poland, Portugal, Spain, and Switzerland. 
up in the labor economics literature. Lloyd (1999) cites French firing regulations that depend on the number of employees in the firm. Additionally, when comparing U.S. and Portuguese labor market flows, Blanchard and Portugal (2001) adjust for firm size. ${ }^{10}$

Due to union contracts and government regulation there is firing delay $\Delta$, i.e., the firm has to wait before the firing happens and would pay the firing costs at the end of the firing delay. We call the hiring and firing costs and the firing delay as frictions. We assume that $C_{H}+C_{F} \geq 0$ and $c_{H}+c_{F} \geq 0$. That is, even though some of the costs could be negative, e.g., due to the government subsidies we assume that there is no possibility for immediate positive cash flows by hiring and firing at the same time, otherwise the value function could be infinite.

Formally, a hiring and firing control policy $\pi$ is a collection $\left\{t_{i}^{\pi}, s_{i}^{\pi}, X_{i}^{\pi}\right\}$, where $t_{i}^{\pi}$ is an increasing sequence of hiring and firing times, $s_{i}^{\pi}$ is a sequence of the binary variable that expresses whether the decision is to hire $\left(s_{i}^{\pi}=H\right)$ or to fire $\left(s_{i}^{\pi}=F\right), X_{i}^{\pi}$ is the amount of workers hired or fired at $i$ 'th hiring/firing time. We assume that each $t_{i}^{\pi}$ is a stopping time of the filtration $\mathcal{F}_{t}$. The binary variable $s_{i}^{\pi}$ is $\mathcal{F}_{t_{i}^{\pi}-}-$ measurable. Further, if at time $t_{i}^{\pi}$ the company decides to hire then $X_{i}^{\pi}$ is also measurable with respect to $\mathcal{F}_{t_{i}^{\pi}-}$, and if it decides to fire then $X_{i}^{\pi}$ is measurable

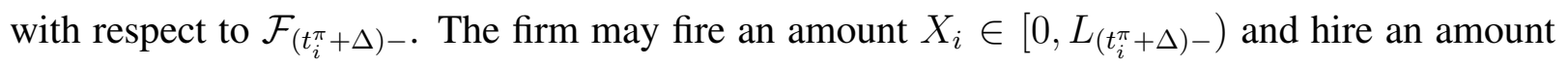
$X_{i} \geq 0$. Additionally, admissible controls must satisfy

$$
t_{i+1}^{\pi}-t_{i}^{\pi} \geq \Delta \text { if } s_{i}^{\pi}=F \text { for all } i \geq 1
$$

As mentioned earlier, the positive parameter $\Delta$ is the delay associated with the firing. When a firing process is started at time $t_{i}^{\pi}$, the workers leave at time $t_{i}^{\pi}+\Delta$. This delay corresponds to the laws, regulatory processes, and work agreements in the region where the company operates. The

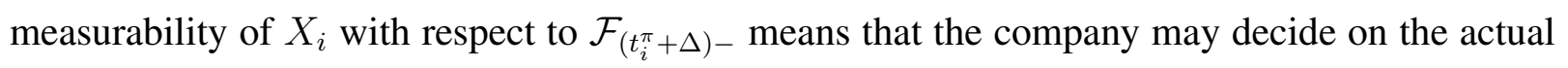
amount of people to be fired at time $t_{i}^{\pi}+\Delta$ based on all then available information, i.e., they do not need to precommit to any amount of people at time $t_{i}$ when they start the firing process. Condition (4) states that a new hiring or firing process may not be started while a previous one is still waiting to be completed. These conditions have important technical merit, but also have a practical justification, in that ruling out hiring while a firing process is under way is likely to make

\footnotetext{
${ }^{10}$ Related to this, according to Hamermesh (1989) and Caballero et al. (1997) plant level fixed labor adjustment costs are significant. However, Cooper and Willis (2004) challenge this result.
} 
the ongoing process successful. Thus, we simply think of constraint (4) as a restriction set by the regulations, work agreements, and job markets. The class of admissible policies satisfying the restrictions in (4) along with conditions on $X$ stated above, $s_{i} \in\{H, F\}$, and $t_{1} \geq 0$ is denoted by $\Pi$. We define the initial decision as $t_{0}=0, s_{0}=H, X_{0}=0$ for mathematical convenience later, but with no hiring costs.

\subsection{Value of the firm}

Assume that no firing is being processed. Given the current labor $L$ and the current demand $\tilde{Z}$, the value of the company under policy $\pi \in \Pi$ is the expected net present value

$$
\begin{aligned}
\tilde{V}_{\pi}\left(A_{0}, \tilde{Z}_{0}, L_{0}\right)= & E\left[\int_{0}^{\infty} e^{-r t}\left(\tilde{Z}_{t}^{1-\lambda}\left(A_{t} L_{t}\right)^{\lambda}-\omega L_{t}\right) d t\right. \\
& -\sum_{i} e^{-r t_{i}^{\pi}} I_{\left\{s_{i}^{\pi}=H\right\}}\left(X_{i}^{\pi} c_{H}+C_{H} L_{t_{i}^{\pi}-}\right) \\
& \left.-\sum_{i} e^{-r\left(t_{i}^{\pi}+\Delta\right)} I_{\left\{s_{i}^{\pi}=F\right\}}\left(X_{i}^{\pi} c_{F}+C_{F} L_{\left(t_{i}^{\pi}+\Delta\right)-}\right)\right]
\end{aligned}
$$

where $I_{\{\cdot\}}$ is the indicator function of the event in the braces,

$$
\begin{gathered}
d L_{t}=-\delta L_{t} d t, \quad L_{t_{i}^{\pi}+\Delta_{i}}=L_{\left(t_{i}^{\pi}+\Delta_{i}\right)-}+X_{i}^{\pi}\left(I_{\left\{s_{i}^{\pi}=H\right\}}-I_{\left\{s_{i}^{\pi}=F\right\}}\right), \\
\Delta_{i}= \begin{cases}0, & \text { if } s_{i}^{\pi}=H \\
\Delta, & \text { if } s_{i}^{\pi}=F .\end{cases}
\end{gathered}
$$

Equation (5) implies that the value of the firm is equal to the expected discounted revenues minus the expected discounted labor, hiring, and firing costs. Note that the value depends on the current demand, productivity, and labor. The expectation can be viewed as a risk-neutral expectation (e.g. Björk (2004)) and $r$ as a risk-free interest rate. In this case, (5) is the riskneutral pricing equation for the firm's cash flows, $W_{t}^{a}$ and $\tilde{W}_{t}$ in $(2)$ and $(3)$ are standard Wiener processes under the risk-neutral probability.

To simplify the model we introduce a new factor, $Z_{t}=\tilde{Z}_{t} a_{t}^{\frac{\lambda}{1-\lambda}}$, which is driven by the demand and productivity uncertainties. Therefore, we call $Z_{t}$ as a demand and productivity risk factor. 
By Ito's lemma, we have

$$
d Z_{t}=\mu Z_{t} d t+\sigma Z_{t} d W_{t}
$$

where

$$
\begin{aligned}
\mu & =\tilde{\mu}+\frac{\lambda}{1-\lambda} \mu_{a}+\frac{1}{2} \frac{\lambda(2 \lambda-1)}{(1-\lambda)^{2}} \sigma_{a}^{2}+\frac{\lambda}{1-\lambda} \rho \tilde{\sigma} \sigma_{a}, \\
\sigma & =\sqrt{\tilde{\sigma}^{2}+\frac{\lambda^{2}}{(1-\lambda)^{2}} \sigma_{a}^{2}+\frac{2 \lambda}{1-\lambda} \rho \tilde{\sigma} \sigma_{a}},
\end{aligned}
$$

and $W_{t}$ is a standard Wiener process given by

$$
W_{t}=\frac{1}{\sigma}\left[\tilde{\sigma} \tilde{W}_{t}+\frac{\lambda}{1-\lambda} \sigma_{a} W_{t}^{a}\right] .
$$

Thus, the demand and productivity risk factor follows a geometric Brownian motion process and, hence, $Z_{t}=Z_{0} e^{\left(\mu-\frac{1}{2} \sigma^{2}\right) t+\sigma W_{t}}$. Note that typically the inverse of the markup factor satisfies $\lambda \in(0,1)$ and, therefore, if the correlation between the productivity and demand is nonnegative (i.e. $\rho \geq 0$ ) then the volatility of $Z$ is higher than the volatility of $\tilde{Z}$ (i.e. $\sigma \geq \hat{\sigma}$ ). More generally, if $\sigma_{a}>2 \frac{\lambda-1}{\lambda} \rho \tilde{\sigma}$ then $\sigma>\hat{\sigma}$. On the other hand, the drift term $\mu$ rises in drift terms $\tilde{\mu}$ and $\mu_{a}$ and correlation $\rho$.

By using $Z_{t},(5)$ can be written as follows

$$
\begin{aligned}
V_{\pi}\left(Z_{0}, L_{0}\right)= & E\left[\int_{0}^{\infty} e^{-r t}\left(Z_{t}^{1-\lambda}\left(A L_{t}\right)^{\lambda}-\omega L_{t}\right) d t\right. \\
& -\sum_{i} e^{-r t_{i}^{\pi}} I_{\left\{s_{i}^{\pi}=H\right\}}\left(X_{i}^{\pi} c_{H}+C_{H} L_{t_{i}^{\pi}-}\right) \\
& \left.-\sum_{i} e^{-r\left(t_{i}^{\pi}+\Delta\right)} I_{\left\{s_{i}^{\pi}=F\right\}}\left(X_{i}^{\pi} c_{F}+C_{F} L_{\left(t_{i}^{\pi}+\Delta\right)-}\right)\right],
\end{aligned}
$$

which corresponds to a problem with random demand $Z_{t}$ and constant productivity $A$. However, due to reduction of dimensionality, (7) is easier to solve than (5). 
The objective is to find an admissible strategy that maximizes the net present value. That is,

$$
V\left(Z_{0}, L_{0}\right)=\sup _{\pi \in \Pi} V_{\pi}\left(Z_{0}, L_{0}\right)
$$

We call $V(\cdot, \cdot)$ as the value function. A sufficient condition for $V(\cdot, \cdot)<\infty$ is that $r>\mu$. An upper bound of $(8)$ is the value of the firm with no frictions:

Lemma 2.1. (Firm value with no frictions) Assume $\mu<r$ and no labor market frictions, i.e., $\Delta=c_{H}=c_{F}=C_{H}=c_{F}=0$. Then given initial demand and productivity risk factor $Z_{0}$, the firm value is

$$
V_{N F}\left(Z_{0}\right)=\frac{\left(A^{\lambda} \eta^{* \lambda}-\omega \eta^{*}\right) Z_{0}}{r-\mu}
$$

where $\eta^{*}=\left(A^{\lambda} \lambda / \omega\right)^{1 /(1-\lambda)}$.

Value $V_{N F}$ is independent of the initial labor level because the labor can be adjusted without frictions. Equation $(9)$ is obtained by maximizing the flow profit that equals $Z_{t}^{1-\lambda}\left(A L_{t}\right)^{\lambda}-\omega L_{t}$ at time $t$. First order condition gives the optimal labor: $L_{t}^{*}=\left(A^{\lambda} \lambda / \omega\right)^{1 /(1-\lambda)} Z_{t}$, which is equivalent to setting the firm's marginal revenue product of labor $\left(M R P L=\lambda A^{\lambda}\left(\frac{Z}{L}\right)^{1-\lambda}\right)$ equal to the wage. Constant $\eta^{*}$ in $(9)$ is the optimal ratio of labor to the demand and productivity risk factor, $L^{*} / Z$, and the same ratio is used in the general case with frictions. Clearly, $V_{N F}\left(Z_{0}\right)$ is an upper bound for the value of the firm in the case with labor market frictions.

The lower bound of 8 is the value of the firm with high frictions. In the appendix we prove that this lower bound is given by the following lemma.

Lemma 2.2. (Firm value with high frictions) Assume either $C_{H}=\infty$ or $c_{H}=\infty$, and either $C_{F}=\infty$ or $c_{F}=\infty$ or $\Delta=\infty$. Further, assume $\lambda \delta+r-(1-\lambda)\left(\mu-\frac{1}{2} \lambda \sigma^{2}\right)>0$. Then there is no hiring and firing, and the firm value is

$$
V_{H F}\left(Z_{0}, L_{0}\right)=\frac{A^{\lambda} Z_{0}^{1-\lambda} L_{0}^{\lambda}}{\lambda \delta+r-(1-\lambda)\left(\mu-\frac{1}{2} \lambda \sigma^{2}\right)}-\frac{\omega L_{0}}{r+\delta} .
$$

Value $V_{H F}$ depends on both the labor level and the demand because the labor cannot be adjusted. Equation (10) is received by setting $t_{i}^{\pi}=\infty$ for all $i$ in (7), and then just calculating the expectation (see the appendix). Since there is no hiring and firing, $V_{H F}\left(Z_{0}, L_{0}\right)$ is a lower 
bound for the value of the firm, and the difference between $V_{N F}$ and $V_{H F}$ is an upper bound for the value decrease due to the labor market frictions.

The following proposition presents some properties of the value function and the proof is in the appendix.

Proposition 2.3. (Value function properties) The value function $V(\cdot, \cdot)$ defined in (8) has the following properties:

(i) $V(\cdot, \cdot)$ is non-increasing in the hiring and firing costs $c_{H}, C_{H}, c_{F}$, and $C_{F}$ and in the firing delay $\Delta$.

(ii) $V(\cdot, \cdot)$ is concave when $\Delta=C_{F}=C_{H}=0$.

Thus, the hiring and firing frictions do not help the firm. It is worthwhile pointing out that the value function may not be concave when one of $\Delta, C_{F}$, and $C_{H}$ is positive.

\subsection{Hamilton-Jacobi-Bellman equation}

Now let us derive the HJB equation for the value function $V(\cdot, \cdot)$ in $(8)$.

Define the infinitesimal generator $\mathcal{L}$ for all $Z>0$ and $L>0$ as follows

$$
\mathcal{L} V(Z, L)=\frac{1}{2} \sigma^{2} Z^{2} \frac{\partial^{2} V(Z, L)}{\partial Z^{2}}+\mu Z \frac{\partial V(Z, L)}{\partial Z}-\delta L \frac{\partial V(Z, L)}{\partial L}-r V(Z, L)
$$

Then, the following result gives the necessary conditions for optimum by using standard arguments (see e.g. Højgaard and Taksar, 1999, Fleming and Soner, 1993, or Oksendal and Sulem, 2002).

Proposition 2.4. (Optimality) Assume $V(Z, L)$ is twice continuously differentiable with respect to $Z$ and once with respect to $L$ on $(0, \infty) \times(0, \infty) .{ }^{11}$ Then it has the following properties for all $Z>0$ and $L>0$.

(i) Hiring is an option:

$$
V(Z, L) \geq \sup _{x>0}\left[V(Z, L+x)-c_{H} x\right]-C_{H} L .
$$

\footnotetext{
${ }^{11}$ Strictly speaking, the value function is not always twice continuously differentiable. However, by viscosity solution, it can be shown that Ito's lemma still works for the value function and the proposition remains valid (see e.g. Crandall et al. (1992)).
} 
(ii) Firing is an option with a delay of $\Delta$ :

$$
V(Z, L) \geq U(Z, L, 0)
$$

where $U\left(Z_{s}, L_{s}, s\right)$ represents the expected discounted firing value at time $s \in[0, \Delta]$, i.e.,

$$
\begin{aligned}
U\left(Z_{s}, L_{s}, s\right)= & E\left[\int_{s}^{\Delta} e^{-r(t-s)}\left(Z_{t}^{1-\lambda}\left(A L_{t}\right)^{\lambda}-\omega L_{t}\right) d t\right. \\
& \left.+e^{-r(\Delta-s)} \sup _{x \in\left[0, L_{\Delta}\right)}\left(V\left(Z_{\Delta}, L_{\Delta}-x\right)-c_{F} x-C_{F} L_{\Delta}\right) \mid \mathcal{F}_{s}\right] .
\end{aligned}
$$

(iii) The value is expected to fall at least by the flow profit:

$$
\mathcal{L} V(Z, L)+Z^{1-\lambda}(A L)^{\lambda}-\omega L \leq 0
$$

(iv) One of the above inequalities is tight for any $Z>0$ and $L>0$, that is,

$$
\begin{aligned}
& \max \left\{\quad \mathcal{L} V(Z, L)+Z^{1-\lambda}(A L)^{\lambda}-\omega L,\right. \\
& \sup _{x>0}\left[V(Z, L+x)-c_{H} x\right]-C_{H} L-V(Z, L) \text {, } \\
& U(Z, L, 0)-V(Z, L) \quad\}=0 .
\end{aligned}
$$

Inequalities (11) and (12) hold for all $Z>0$ and $L>0$ because a hiring or firing decision can be started at any time. In the same way, inequality (14) must hold since waiting is always an admissible policy. Equation (15) is the HJB equation derived from the the first order condition of our problem. Mathematically, this type of equations is known as the quasi-variational inequality equation.

By (13), $U(Z, L, s)$ satisfies

$$
\left\{\begin{array}{l}
U_{s}(Z, L, s)+\mathcal{L} U(Z, L, s)+Z^{1-\lambda}(A L)^{\lambda}-\omega L=0 \text { for } Z>0, L>0, \text { and } s \in[0, \Delta), \\
U(Z, L, \Delta)=\sup _{x \in[0, L)}\left[V(Z, L-x)-c_{F} x\right]-C_{F} L,
\end{array}\right.
$$


which is coupled with equation (15). As such, we need to solve a system of equations (15)-(16).

It is not hard to verify that value function $V$ is homogeneous in $Z$ and $L$, i.e.,

$$
V(k Z, k L)=k V(Z, L)
$$

for all $k>0$. This homogeneity enables us to make use of the following transformations:

$$
\eta=\frac{L}{Z}, f(\eta)=\frac{V(Z, L)}{Z}, g(\eta, s)=\frac{U(Z, L, s)}{Z} .
$$

Then, equations (15)-(16) are reduced to

$$
\begin{gathered}
\max \left\{\mathcal{A} f(\eta)+(A \eta)^{\lambda}-\omega \eta, \quad \sup _{m>0}\left[f(\eta+m)-c_{H} m\right]-C_{H} \eta-f(\eta),\right. \\
g(\eta, 0)-f(\eta)\}=0 \text { for } \eta>0
\end{gathered}
$$

and

$$
\left\{\begin{array}{l}
g_{s}(\eta, s)+\mathcal{A} g(\eta, s)+(A \eta)^{\lambda}-\omega \eta=0 \text { for } \eta>0 \text { and } s \in[0, \Delta) \\
g(\eta, \Delta)=\sup _{m \in[0, \eta)}\left[f(\eta-m)-c_{F} m\right]-C_{F} \eta,
\end{array}\right.
$$

respectively, where

$$
\mathcal{A} \phi(\eta, t)=\frac{1}{2} \sigma^{2} \eta^{2} \frac{\partial^{2} \phi(\eta, t)}{\partial \eta^{2}}-(\mu+\delta) \eta \frac{\partial \phi(\eta, t)}{\partial \eta}-(r-\mu) \phi(\eta, t)
$$

Equation (18) implies that there are three regions: the firing region (FR), the hiring region (HR), and the no-action region (NR), defined as follows

$$
\begin{aligned}
H R & =\left\{\eta: f(\eta)=\sup _{m>0}\left[f(\eta+m)-c_{H} m\right]-C_{H} \eta\right\} \\
F R & =\{\eta: f(\eta)=g(\eta, 0)\} \\
N R & =\left\{\eta: f(\eta)>\max \left(g(\eta, 0), \sup _{m>0}\left[f(\eta+m)-c_{H} m\right]-C_{H} \eta\right)\right\} .
\end{aligned}
$$

To understand better these regions we give the following proposition and the proof is in the 
appendix.

Proposition 2.5. (Barriers and variable costs) Assume the firm-sized costs and the firing delay are zero, i.e., $C_{H}=C_{F}=\Delta=0$. Then we have:

(i) There are two constants $b_{H}<b_{F}$ such that the firing, hiring, and no-action regions are given by

$$
\begin{aligned}
H R & =\left\{\eta: \eta \leq b_{H}\right\}, \\
F R & =\left\{\eta: \eta \geq b_{F}\right\}, \\
N R & =\left\{\eta: b_{H}<\eta<b_{F}\right\} .
\end{aligned}
$$

(ii) The firing barrier $b_{F}$ is increasing in variable costs $c_{H}$ and $c_{F}$, and the hiring barrier $b_{H}$ is decreasing in variable costs $c_{H}$ and $c_{F}$.

Thus, by $(i)$, if there are no firm-sized costs and no firing delay then two barriers $\left(b_{H}\right.$ and $b_{F}$ ) define the HR, FR, and NR regions. Further, by $(i i)$, when the variable costs increase, the no-action region gets wider. If the assumption of Proposition 2.5 is violated, it is difficult to prove $(i)$ and $(i i)$. However, by our numerical results (Figures $3 \mathrm{a}-8$ for part $(i)$ and Figures 7 and 8 for part $(i i)$ ), Proposition 2.5 holds even if the assumption does not hold. ${ }^{12}$ Thus, in general we have:

- for all $\eta$ in $H R\left(\eta \in\left(0, b_{H}\right]\right)$, it is optimal to hire workers;

- for all $\eta$ in $F R\left(\eta \in\left[b_{F}, \infty\right)\right)$, it is optimal to start the firing process;

- for all $\eta$ in $N R\left(\eta \in\left(b_{H}, b_{F}\right)\right)$, it is optimal neither to hire new workers nor to fire workers.

Denote

$$
\begin{aligned}
m_{H} & =\underset{m>0}{\operatorname{argsup}}\left[f\left(b_{H}+m\right)-c_{H} m\right], \\
m_{F}(\eta) & =\underset{0 \leq m<\eta}{\operatorname{argsup}}\left[f(\eta-m)-c_{F} m\right] .
\end{aligned}
$$

\footnotetext{
${ }^{12}$ We solve 18 - 19 by using a finite difference method with penalty approximation (see, e.g., Forsyth and Vetzal, 2002, Dai et al. 2007).
} 
We then define target barriers as follows

$$
u_{H}=b_{H}+m_{H}, \quad u_{F}(\eta)=\eta-m_{F}(\eta)
$$

The target barriers are the optimal $\eta$ levels to which hire up or fire down. Note that $u_{F}(\eta)$ depends on $\eta$ and, therefore, to illustrate the hiring and firing policy, we define the expected firing target in the beginning of the firing process as follows

$$
\bar{u}_{F}=E_{t_{i}^{\pi}}\left[u_{F}\left(\eta_{t_{i}^{\pi}+\Delta}\right)\right]
$$

when $s_{i}^{\pi}=F$. Here $E_{t_{i}^{\pi}}[\cdot]$ is the expectation conditional on information in the beginning of the firing process and, thus, $\bar{u}_{F}$ is the expected target level of the labor to the demand and productivity risk factor ratio after the firing process.

Given the target barriers $u_{H}$, and $u_{F}(\cdot)$ and the barriers of Proposition 2.5, $b_{H}$ and $b_{F}$, we generate a policy $\pi$ that follows this barrier structure. First define $t_{0}=0, s_{0}=H, m_{0}=0$ without any cost at $t_{0}$ for ease of notation. Then $t_{i+1}=\inf \left\{t: \eta \notin\left(b_{H}, b_{F}\right), t>t_{i+\Delta_{i}}\right\}$, where $\Delta_{i}=0$ if $s_{i}=H$ and $\Delta_{i}=\Delta$ if $s_{i}=F, s_{i+1}=H$ if $\eta_{t_{i}+1}=b_{H}$ and $s_{i+1}=F$ if $\eta_{t_{i}+1}=b_{F}$, $m_{i+1}=u_{H}-b_{H}$ if $s_{i+1}=H$ and $m_{i+1}=\eta_{t_{i+1}+\Delta}-u_{F}\left(\eta_{t_{i+1}+\Delta}\right)$ if $s_{i+1}=F$. The evolution of a path of $\eta$ is represented in Figure 2 given target barrier $u_{H}$, expected target barrier $\bar{u}_{F}$ (for simplicity, we assume in the figure that $\left.\bar{u}_{F}=u_{F}\left(\eta_{t_{i}+\Delta}\right)\right)$, and impulse control barriers $b_{H}$ and $b_{F}$.

\section{Comparative statics}

In this section we analyze the impact of different model parameters on the optimal hiring and firing policy and the value of the firm. We solve the optimal policy numerically by applying a finite difference method and the value-matching and the smooth-pasting conditions to (18)-(19) (see e.g. Gustafsson 2011 and Wilmott 2007). We illustrate the effects of the model parameters with figures and different elasticity estimates. Note that in the comparative statics the realized target level $u_{F}(\eta)$ might be different from the expected target level $\bar{u}_{F}$ presented in the figures. Therefore, the realized firing action is not exactly $b_{F}-\bar{u}_{F}$. 


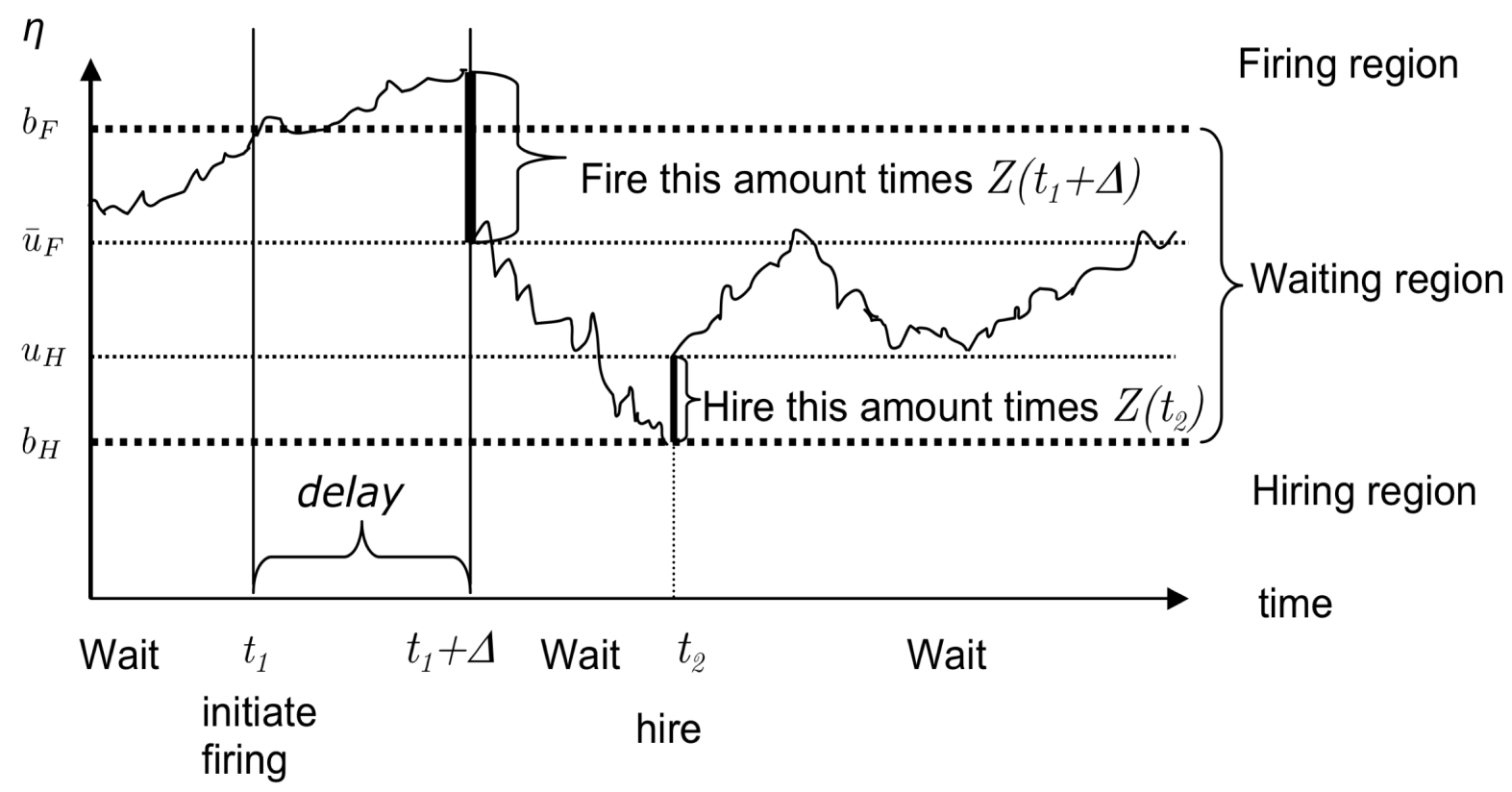

Figure 2: Evolution of $\eta$.

We choose the baseline parameter values by using Bloom (2009) who considers a firm's hiring and firing policies as well as capital investments and estimates the model parameters based on U.S. Compustat data between 1981 and 2000. To convert his parameter estimates to the corresponding parameters in our model, we ignore the capital investments and also his quadratic labor adjustment costs. This gives Table 1 .

Matching the Bloom's model and our model gives

$$
\begin{array}{ll}
\lambda=b=1-1 / \epsilon, \quad A=\tilde{A} H, & \omega=\omega_{1}\left(1+\omega_{2} H^{\gamma}\right), \\
c_{H}=c_{F}=\omega_{1}\left(1+\omega_{2} H^{\gamma}\right) C_{L}^{P}, & C_{H}=C_{F}=C_{L}^{F} B^{1-b}(\tilde{A} H L)^{b} / L .
\end{array}
$$

We select $L_{0}=1000$, i.e., the firm has initially thousand employees, $H=1$ year, i.e., the working time unit is one year (and not hours as in Bloom 2009), $\tilde{A}=1$, i.e., each worker produces one product per annum. Further, we set the firing delay $\Delta$ to equal half a year, which is about in the middle of the range observed in Figure 1 1 These give our baseline parameter values for the comparative statics (see Table 2). By the parameter values, the firm's revenue 
Table 1: Bloom (2009) and our model. Parameters in the Bloom's model: $\tilde{A}$ is the productivity of the employees, $B$ is a demand shifter, $L$ is labor, $H$ is hours worked, $b=1-1 / \epsilon$ where $\epsilon$ is the elasticity of demand, $\omega_{1}, \omega_{2}$, and $\gamma$ are parameters of the wage equation, $E^{+}$is the number of employees hired, $E^{-}$is the number of employees fired, $C_{L}^{P}$ is per capita hiring/firing cost and $C_{L}^{F}$ is fixed hiring/firing cost (see Bloom 2009).

\begin{tabular}{c|c}
\hline & Bloom's model \\
\hline Revenue & $B^{1-b}(\tilde{A} H L)^{b}$ \\
Labor Wage Cost & $\omega_{1}\left(1+\omega_{2} H^{\gamma}\right) L$ \\
Adjustment Cost & $\omega_{1}\left(1+\omega_{2} H^{\gamma}\right) C_{L}^{P}\left(E^{+}+E^{-}\right)+C_{L}^{F} I_{\{E \neq 0\}} B^{1-b}(\tilde{A} H L)^{b}$ \\
\hline \hline & Our model \\
\hline Revenue & $Z^{1-\lambda}(A L)^{\lambda}$ \\
Labour Wage Cost & $\omega L$ \\
Adjustment Cost & $I_{\left\{s_{i}^{\hat{\hat{\pi}}}=H\right\}}\left(X_{i}^{\hat{\pi}} c_{H}+C_{H} L_{t_{i}^{\hat{\hat{\tau}}}}\right)+I_{\left\{s_{i}^{\hat{\hat{n}}}=F\right\}}\left(X_{i}^{\hat{\pi}} c_{F}+C_{F} L_{t^{\hat{\pi}}+\Delta}\right)$ \\
\hline
\end{tabular}

per annum is 135.1 million dollars and the net income without hiring and firing cost is 35.1 million dollars. Further, by Lemma 2.1 and Lemma 2.2, the firm value without the labor market frictions $V_{N F}(1000 / 0.3) \approx 781$ million dollars and the firm value with high labor market frictions $V_{H F}(1000 / 0.3,1000) \approx 295$ million dollars, where $\eta_{0}=0.3, L_{0}=1000$, and $Z=L / \eta$. The difference between $V_{N F}$ and $V_{H F}$ is an upper bound for the value decrease due to the labor market frictions, and under the baseline parameters this upper bound is about $62 \%$ of $V_{N F}$. By (17), the $V_{N F}$ corresponds to $f_{N F}(0.3)=V_{N F}(1000 / 0.3) \cdot 0.3 / 1000 \approx 234,375$ and the $V_{H F}$ corresponds to $f_{H F}(0.3)=V_{H F}(1000 / 0.3,1000) \cdot 0.3 / 1000 \approx 88,422$. Since money metric variables are in terms of one hundred thousand dollars (see Table 2), we write $f_{N F}(0.3) \approx 2.34$ and $f_{H F}(0.3) \approx 0.88$. By Lemma 2.1, the corresponding no friction $\eta^{*} \approx 0.32$ that allows us to define the corresponding initial no friction labor level as $L_{0}^{*}=Z_{0} \cdot \eta^{*} \approx 1055$. That is, the no friction labor level is about $5.5 \%$ higher than our initial labor level.

Table 2: Baseline parameter values. Parameters are from Table 1 and Bloom (2009) (Table II and Table III under "All Adjustment Costs Specification"). The time unit is year and the money metric variables $\left(\omega, c_{H}, c_{F}, C_{H}, C_{F}\right)$ are in terms of one hundred thousand dollars.

\begin{tabular}{c|cccccccccc}
\hline Parameter & $\lambda$ & $\omega$ & $\delta$ & $r$ & $\mu$ & $A$ & $\sigma$ & $c_{H}, c_{F}$ & $C_{H}, C_{F}$ & $\Delta$ \\
\hline Value & 0.75 & 1 & 0.1 & 0.065 & 0.02 & 1 & 0.4 & 0.014 & 0.025 & 0.5 \\
\hline
\end{tabular}




\subsection{Firing delay}

By Figures $3 \mathrm{a}$ (i) and $3 \mathrm{a}(\mathrm{iii})$, delay $\Delta$ has only a weak effect on the hiring and firing policy $\left(b_{F}, u_{F}, u_{H}, b_{H}\right)$ and the firm value $V$ under the baseline parameter values of Table 2 . However, consistent with Proposition 2.3, the value falls in the firing delay. Since the initial $\eta$-value of 0.3 is closer to the hiring barrier, the firm rarely fires as can be seen from Figure $3 \mathrm{a}$ (iv). Further, the hiring and firing policy is not sensitive to the firing delay in this case. Corresponding to the average labor in Figure 3a(ii) we define by Lemma 2.1 no friction average labor level as average $\left(L^{*}\right)$ $=$ average $(Z) \cdot \eta^{*} \approx 1168$ which is higher than the average labor levels in Figure 3a(ii). Thus, due to the labor market frictions the company hedges the risk of having too many workers and this way paying too much wages or firing costs by having less employees than in the no friction case.

To analyze more the sensitivity with respect to the firing delay we calculate the following elasticities for hiring and firing:

$$
\begin{aligned}
& E_{\text {hiring,firing delay }}=\text { average }\left\{\frac{d\left(\frac{\text { hiring quantity }}{\text { labor level }}\right) / \frac{\text { hiring quantity }}{\text { labor level }}}{d \text { (firing delay }) / \text { firing delay }}\right\}=-0.03 \\
& E_{\text {firing,firing delay }}=\text { average }\left\{\frac{d\left(\frac{\text { firing quantity }}{\text { labor level }}\right) / \frac{\text { firing quantity }}{\text { labor level }}}{d(\text { firing delay }) / \text { firing delay }}\right\}=-0.12,
\end{aligned}
$$

where the differential $d x$ represents an infinitely small change in the variable $x$ and the average is over the values in Figure $3 \mathrm{a}$ (iv). Thus, a one percent increase in the firing delay decreases hiring only by about $0.03 \%$ and firing by about $0.12 \%$.

To illustrate that delay has a stronger effect when uncertainty rises, we generate Figure $3 b$ which has twice as high demand and productivity uncertainty as in Figure 3a Figure 3b (i) shows a decreasing trend for the firing barriers as a function of the firing delay. Thus, due to the higher demand and productivity uncertainty, the company prefers to start the firing process earlier when the delay rises. Naturally in this case the labor level in Figure 3b(ii) is also more volatile than in Figure 3a(ii) and, by Figures 3a(iv) and 3b(iv), the probability of reaching the hiring and firing barriers is higher. Thus, the demand and productivity uncertainty raises both hiring and 
firing. The average labor levels in Figure $3 \mathrm{~b}$ (ii) are lower than the corresponding labor levels in Figure 3a(ii) (e.g. the average labor levels at zero firing delay are 1083 and 1141, respectively). This means that due to the labor market frictions and the higher uncertainty, the company hedges the risk of having too many workers and this way paying too much wages or firing costs by having less employees than under the lower uncertainty.

By Figure 3b(iv) and (20), in this case

$$
E_{\text {hiring,firing delay }}=-0.06 \text { and } \quad E_{\text {firing,firing delay }}=-0.10 \text {, }
$$

i.e., a one percent increase in the firing delay decreases hiring by about $0.06 \%$ and firing by about $0.10 \%$, or doubling the firing delay decreases hiring by $6 \%$ and firing by $10 \%$. Note that the firing elasticity is smaller than under the baseline demand and productivity volatility in (20). This is because due to the higher uncertainty and the longer firing delay, the firm needs to start the firing process earlier ( $b_{F}$ falls rapidly in $\Delta$ ) and every time it fires, it is expected to fire less employees $\left(b_{F}-\bar{u}_{F}\right.$ falls in $\left.\Delta\right)$.

When the uncertainty is high and the firing delay is long, the chances that the labor level is far from the optimal level is high and this decreases the value of the firm. ${ }^{13}$ By Figures 3 a(iii) and $3 \mathrm{~b}$ (iii), the firm value under the baseline uncertainty (40\%) falls only about $0.7 \%$ due to lower profitability when the firing delay is raised from zero to one year, while the same number with $\sigma=80 \%$ is about $3.7 \%$. This lower profitability decreases substantially the number of high uncertainty firms. To see this, let us consider also non-labor costs (note that so far we have modeled only labor related costs). Let us assume that the present value of the non-labor costs in the $\eta$-space of $(17)$ is two hundred thousand, which corresponds to $Z_{0} \cdot 200,000=$ $(1000 / 0.3) \cdot 200,000 \approx 666$ million dollars, where initial labor $L_{0}=1000$ and $\eta_{0}=L_{0} / Z_{0}=0.3$. By Figure $3 \mathrm{~b}$ (iii), the high uncertainty firms cannot operate profitable under a firing delay of one year (note that $f(\eta)=2$ means 200,000 because, by Table 2 , money metric variables are in terms of one hundred thousand dollars); however, the firms with the baseline volatility can still survive (see Figure 3a(iii)). Thus, in countries and states with long regulatory firing delays, companies

\footnotetext{
${ }^{13}$ In the high demand and productivity uncertainty case of Figure $3 \mathrm{~b}$, the value functions without labor market frictions and with high labor market frictions are $f_{N F}(0.3) \approx 2.34$ and $f_{H F}(0.3) \approx 0.26$, i.e., the upper bound for the value decrease due to the labor market frictions is about $89 \%$ of $f_{N F}$ (the corresponding number in Figure $3 \mathrm{a}$ is $62 \%)$.
} 
that have high demand or productivity uncertainty are substantially less profitable and, therefore, our model suggests that there are less this kind of companies, which means that the prevalence of companies that have low demand and productivity uncertainty is higher. Since, by Figure 3a(iv), these low uncertainty firms hire and fire less, the high prevalence of the low uncertainty firms decreases job reallocation rates in states and countries with high labor market frictions. This is consistent with Haltiwanger et al. (2014) who find empirically that stringent hiring and firing regulations reduce the pace of job reallocation, and with Davis et al. (2007, 2010) and Decker et al. (2014) who show that the volatility of business growth and job reallocation rates have fallen substantially since 1980. By Davis and Haltiwanger (2014), the decrease in the job reallocation rates is negative for the economy since falling labor market fluidity raises unemployment rates, especially among marginal workers and those with limited skills. Thus, Figure 1 and our results indicate that the long firing delays in several European countries could partially explain the high unemployment rates there, especially among young people. ${ }^{14}$

\subsection{Demand and productivity uncertainty}

The demand and productivity uncertainty has the strongest effect on the hiring and firing policy in our model. When the uncertainty is high, there is high probability that the firm's labor level is far from the optimal level and, therefore, the firm changes substantially its hiring and firing policy. By Figure 4(i), as the volatility rises, all of the barriers except $b_{F}$ fall and there is a significant increase in the hiring and firing percentages in Figure 4(iv). More specifically, by (20), we have

$$
E_{\text {hiring,volatility }}=0.56 \quad \text { and } \quad E_{\text {firing,volatility }}=1.40
$$

i.e., a one percent increase in the volatility increases hiring by about $0.56 \%$ and firing by about $1.40 \%$. This suggests that in countries and states with firms that have high demand or productivity uncertainty, there are high job reallocation rates. Figure 4(ii) illustrates that, as expected, the demand and productivity volatility increases also the standard deviation of the labor level. Thus, as discussed in subsection 3.1, if the demand and productivity uncertainty is low then the company hires and fires less, and this decreases worker reallocate rates. In Figure 4(ii) the aver-

\footnotetext{
${ }^{14}$ See e.g. Eurostat Labour Force Statistics, available at http://ec.europa.eu/eurostat/web/ microdata/european-union-labour-force-survey.
} 


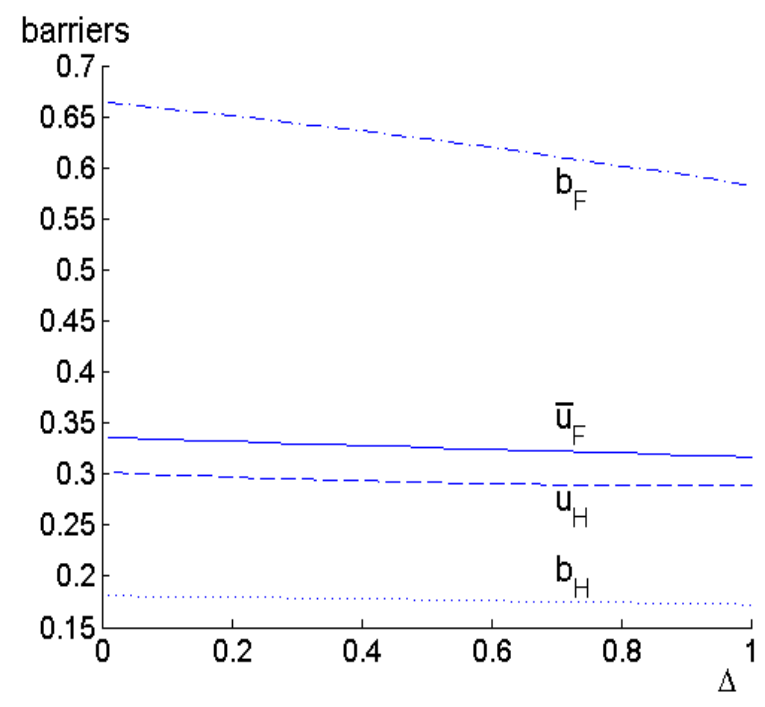

(i) Barriers vs. Delay

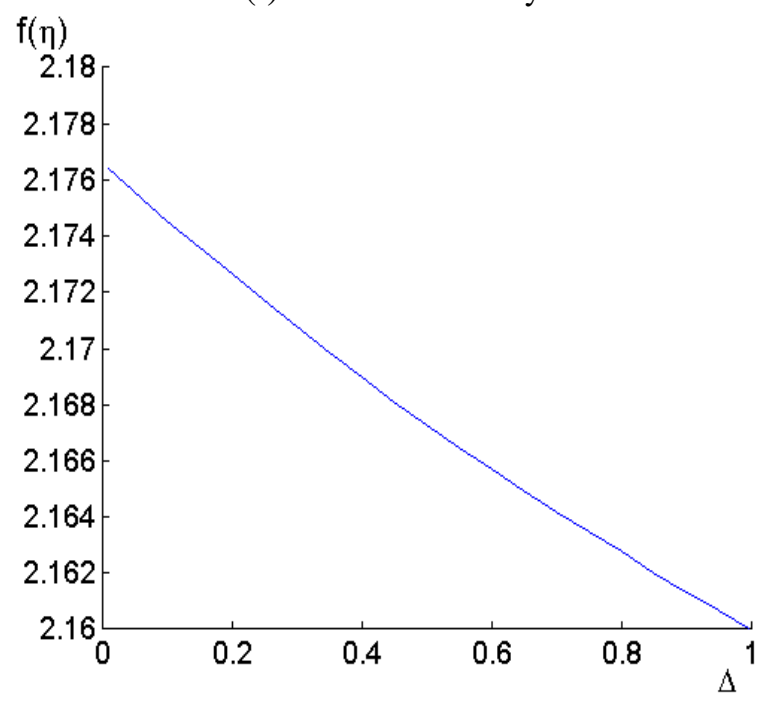

(iii) Value Function vs. Delay

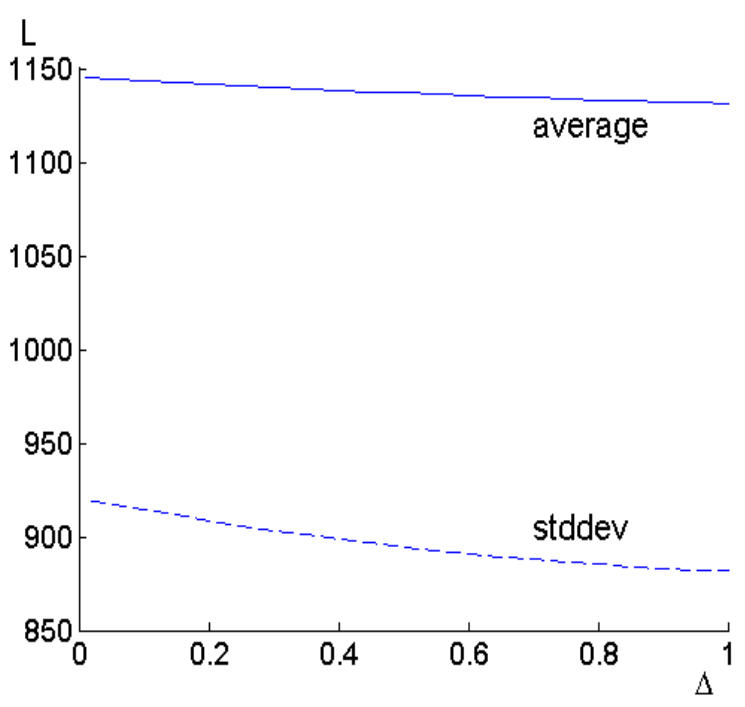

(ii) Labor Level vs. Delay

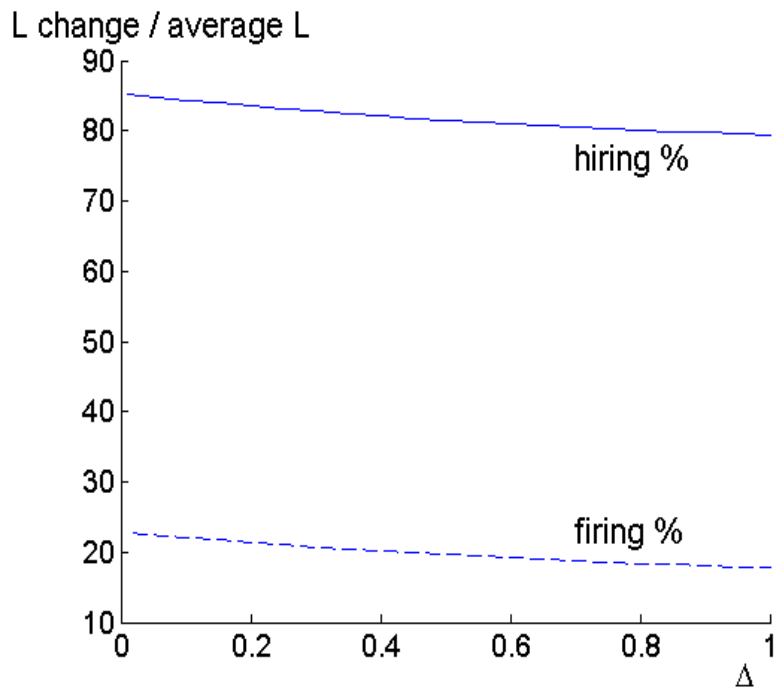

(iv) Hiring and Firing \% vs. Delay

Figure 3a: The effect of firing delay $\Delta$ on optimal strategy $\left(b_{F}, \bar{u}_{F}, u_{H}, b_{H}\right)$, labor level $L$, value function $f(\eta)$, and on hiring and firing relative to the average labor level with the baseline demand and productivity volatility $\sigma$. The model parameters are in Table 2, Figures (ii) and (iv) are calculated by Monte Carlo Simulation with initial value $\eta_{0}=0.3$ and 120 time steps over a ten year time horizon. By Lemma 2.1, in Figures (i) and (ii) the corresponding no friction $\eta^{*} \approx 0.32$ and average no friction labor level average $\left(L^{*}\right)=\operatorname{average}(Z) \cdot \eta^{*} \approx 1168$. By Lemmas 2.1 and 2.2, in Figure (iii) the corresponding value functions without labor market frictions and with high labor market frictions: $f_{N F}(0.3) \approx 2.34, f_{H F}(0.3) \approx 0.88$. 


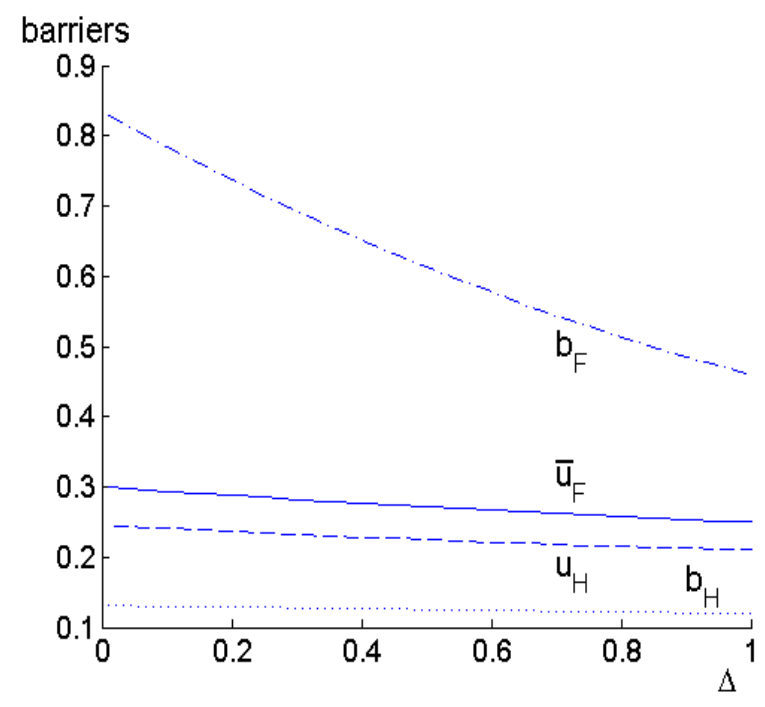

(i) Barriers vs. Delay

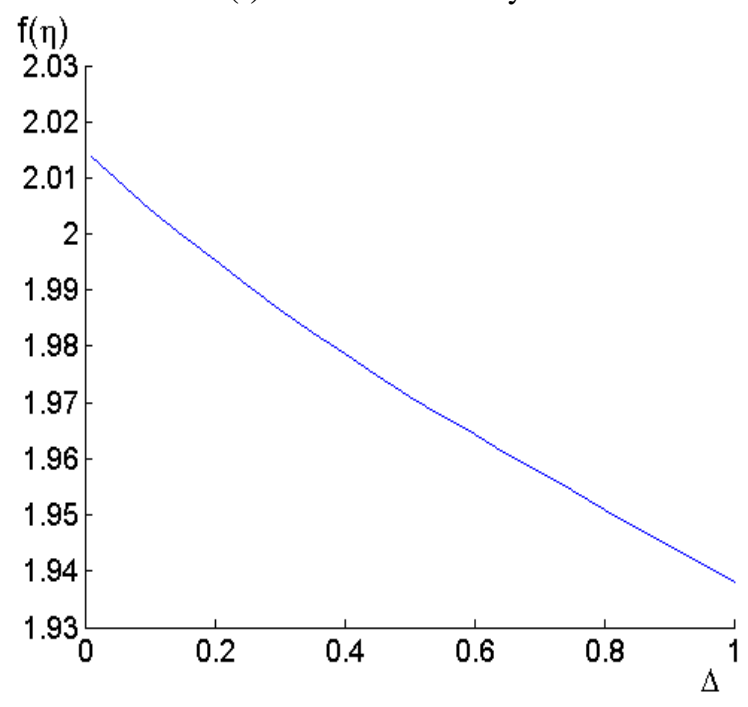

(iii) Value Function vs. Delay

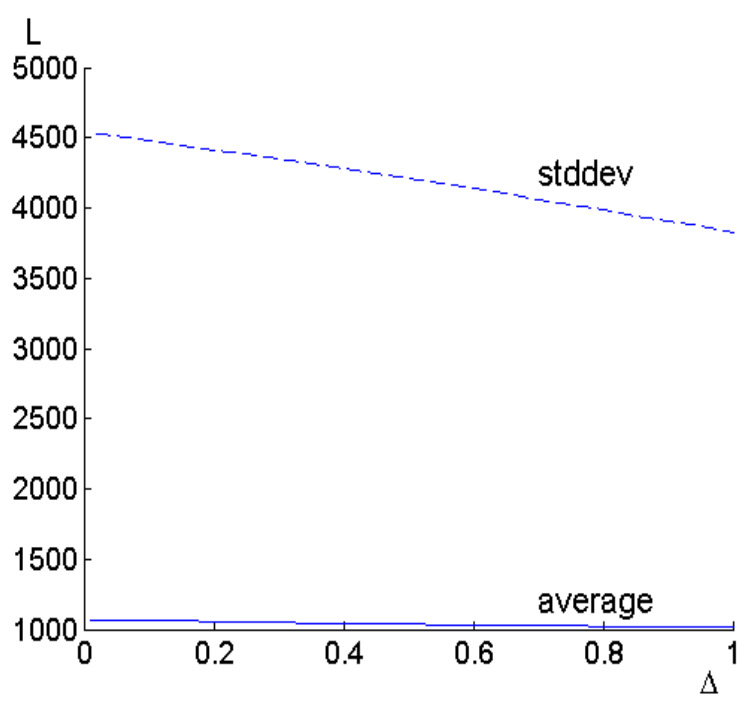

(ii) Labor Level vs. Delay

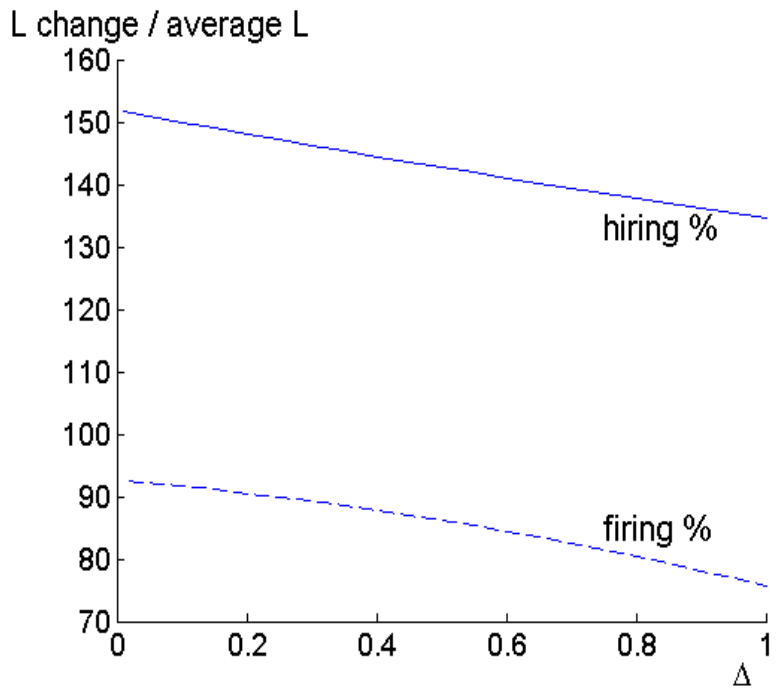

(iv) Hiring and Firing \% vs. Delay

Figure 3b: The effect of firing delay $\Delta$ on optimal strategy $\left(b_{F}, \bar{u}_{F}, u_{H}, b_{H}\right)$, labor level $L$, value function $f(\eta)$, and on hiring and firing relative to the average labor level with high demand and productivity volatility, $\sigma=80 \%$. Other model parameters are in Table 2. Figures (ii) and (iv) are calculated by Monte Carlo Simulation with initial value $\eta_{0}=0.3$ and 120 time steps over a ten year time horizon. By Lemma 2.1, in Figures (i) and (ii) the corresponding no friction $\eta^{*} \approx 0.32$ and average no friction labor level average $\left(L^{*}\right)=\operatorname{average}(Z) \cdot \eta^{*} \approx 1168$. By Lemmas 2.1 and 2.2, in Figure (iii) the corresponding value functions without labor market frictions and with high labor market frictions: $f_{N F}(0.3) \approx 2.34, f_{H F}(0.3) \approx 0.26$. 
age labor level ranges from 1141 to 1072 and the corresponding no friction average labor level, average $\left(L^{*}\right) \approx 1168$. Thus, because the hiring and firing costs decrease the value of employees, even with zero uncertainty the company has less employees than under the no friction case. Further, when the uncertainty rises, the company hedges the risk of having too many workers and this way paying too much wages or firing costs by having less employees than under the zero uncertainty.

As discussed earlier, when the demand and productivity volatility is high then the probability that the labor is far from the optimal level is also high and this decreases the value function as show in Figure 4(iii). For instance, when our baseline volatility $(40 \%)$ is doubled, the firm value falls by about $10 \%$.

\subsection{Firm-sized hiring and firing costs}

In this subsection we analyze firm-sized hiring and firing costs that are motivated by some regulations that apply to only for large firms (e.g. Table 2.A.9 in OECD, 1999).

First, Figure 5 illustrates how firm-sized hiring cost $C_{H}$ affects the hiring and firing policy and the firm value. By Figure 5 (iv) and 20 , we have

$$
E_{\text {hiring,firm-sized hiring cost }}=-0.05 \quad \text { and } \quad E_{\text {firing,firm-sized hiring cost }}=-0.14 \text {, }
$$

i.e., a one percent increase in the firm-sized hiring cost decreases hiring by about $0.05 \%$ and firing by about $0.14 \%$. As with the firing regulatory delay, this implies that in countries and states that have high hiring frictions, there are low job reallocation rates. The hiring trigger barrier $b_{H}$ decreases in $C_{H}$ as shown in Figure 5(i) whereas the optimal hiring target level $u_{H}$ rises. This increases the number of people hired when $\eta$ hits $b_{H}$ and this way the fixed hiring cost per person hired is kept small. Moreover, the firm-sized hiring costs affect the firing barriers as well because the hiring and firing policies interact as show in Figure 5(i). More specifically, when $C_{H}$ rises then the company fires less to avoid future hiring costs and both $b_{F}$ and $\bar{u}_{F}$ increase slightly. By Figure 5(ii), the average labor level falls substantially in the firm-sized hiring cost because then it is less profitable to replace the employees who quit or who have been fired. Under the baseline parameter values of Table 2, when the firm-sized hiring cost is zero then the average 


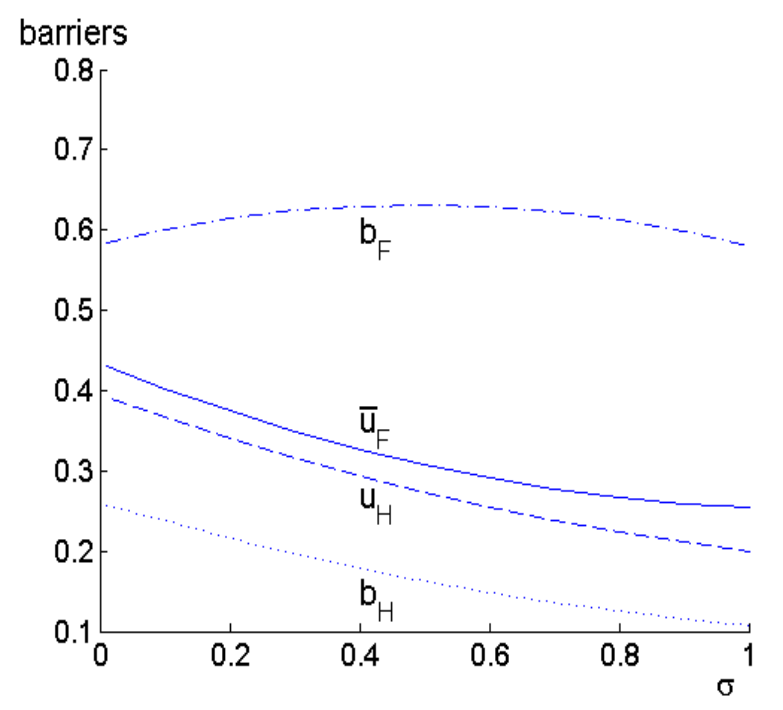

(i) Barriers vs. Volatility

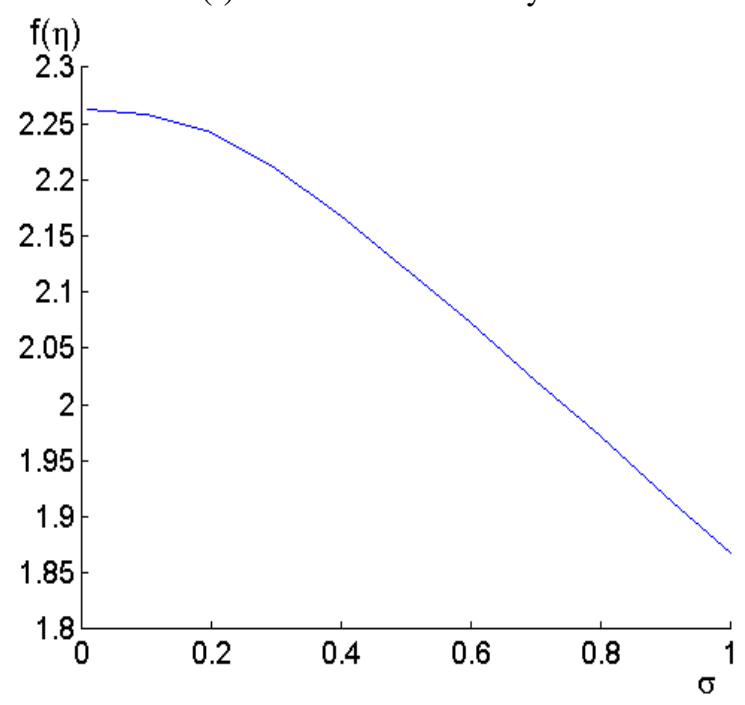

(iii) Value Function vs. Volatility

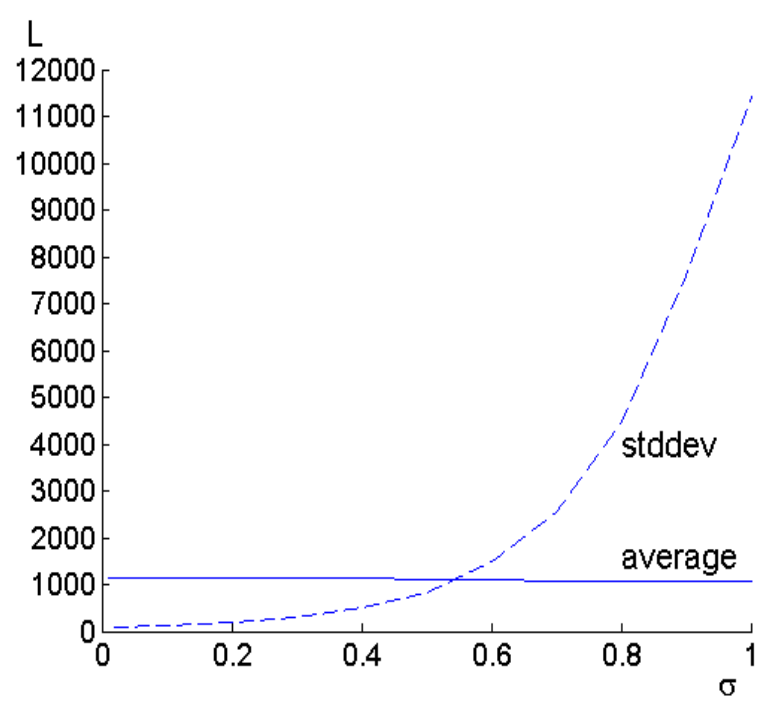

(ii) Labor Level vs. Volatility

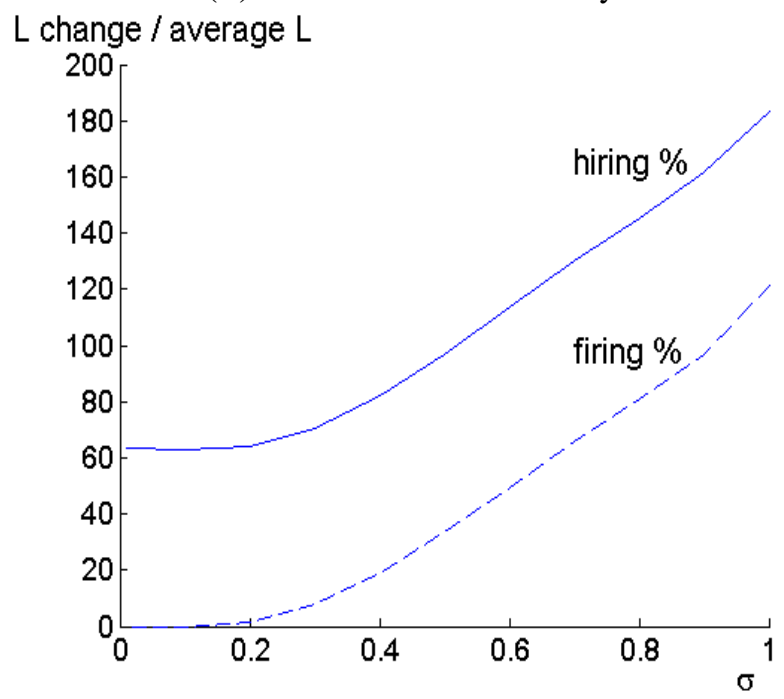

(iv) Hiring and Firing \% vs. Volatility

Figure 4: The effect of demand and productivity volatility $\sigma$ on optimal strategy $\left(b_{F}, \bar{u}_{F}, u_{H}, b_{H}\right)$, labor level $L$, value function $f(\eta)$, and on hiring and firing relative to the average labor level. The model parameters are in Table 2. Figures (ii) and (iv) are calculated by Monte Carlo Simulation with initial value $\eta_{0}=0.3$ and 120 time steps over a ten year time horizon. By Lemma 2.1, in Figures (i) and (ii) the corresponding no friction $\eta^{*} \approx 0.32$ and average no friction labor level average $\left(L^{*}\right)=\operatorname{average}(Z) \cdot \eta^{*} \approx 1168$. By Lemmas 2.1 and 2.2, in Figure (iii) the corresponding value functions without labor market frictions and with high labor market frictions: $f_{N F}(0.3) \approx 2.34, f_{H F}(0.3)$ ranges from 1.18 (when $\sigma$ is zero) to -0.04 ( $\sigma$ equals 1 ). 
labor level is about the same as the corresponding average in the no friction case. By Figure 5 (iii) and Proposition 2.3, the firm value naturally falls in the firm-sized hiring cost because then the profitability decreases.

Second, by Figure 6, firm-sized firing $\operatorname{cost} C_{F}$ has similar but stronger effects. According to Figure 6(iv) and (20), we have

$E_{\text {hiring,firm-sized firing cost }}=-0.13$ and $E_{\text {firing,firm-sized firing cost }}=-0.56$,

i.e., a one percent increase in the firm-sized firing cost decreases hiring by about $0.13 \%$ and firing by about $0.56 \%$. This indicates that in countries and states that have high firing frictions, there are low job reallocation rates. As shown in Figure 6(i), $C_{F}$ raises the cost of firing and, therefore, the firm lowers the probability of firing by raising $b_{F}$. Further, to minimize the effect of the fixed cost, the difference $b_{F}-\bar{u}_{F}$ rises in $C_{F}$ and, thus, every time the firm fires, it fires more employees. Moreover, since the firing cost decreases the value of employees, the company lowers the hiring target barrier $u_{H}$ slightly. By Figure 6(ii), the average labor level falls in the firm-sized firing cost because then the value of the employees fall. Under the baseline parameter values of Table 2, even when the firm-sized firing cost is zero then the average labor level is significantly less than the corresponding average in the no friction case (the average labor levels are 1105 and 1168, respectively). As expected, the firm value falls in $C_{F}$ as shown in Figure 6(iii).

\subsection{Proportional hiring and firing costs}

Next we analyze the proportional hiring and firing costs. They have stronger impact on the optimal policy than the firm-sized costs because the proportional costs penalize every employee hired or fired. These costs have been rising in many countries. For instance, according to Kleiner and Krueger (2013), the share of all workers in US who require government licenses has grown from about $5 \%$ in the 1950 s to $29 \%$ in 2008 , and this raises the hiring costs.

Figure 7 illustrates the effects of proportional hiring cost. By Figure 7 (iv) and $(20)$, we get

$E_{\text {hiring, proportional hiring cost }}=-0.24 \quad$ and $\quad E_{\text {firing, proportional hiring cost }}=-0.58$,

i.e., a one percent increase in the proportional hiring cost decreases hiring by about $0.24 \%$ and 


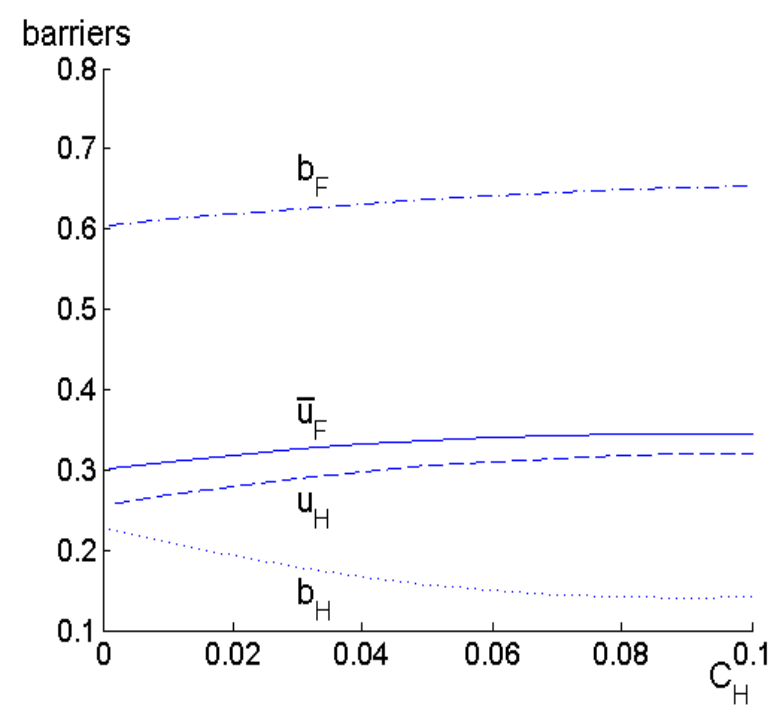

(i) Barriers vs. $C_{H}$

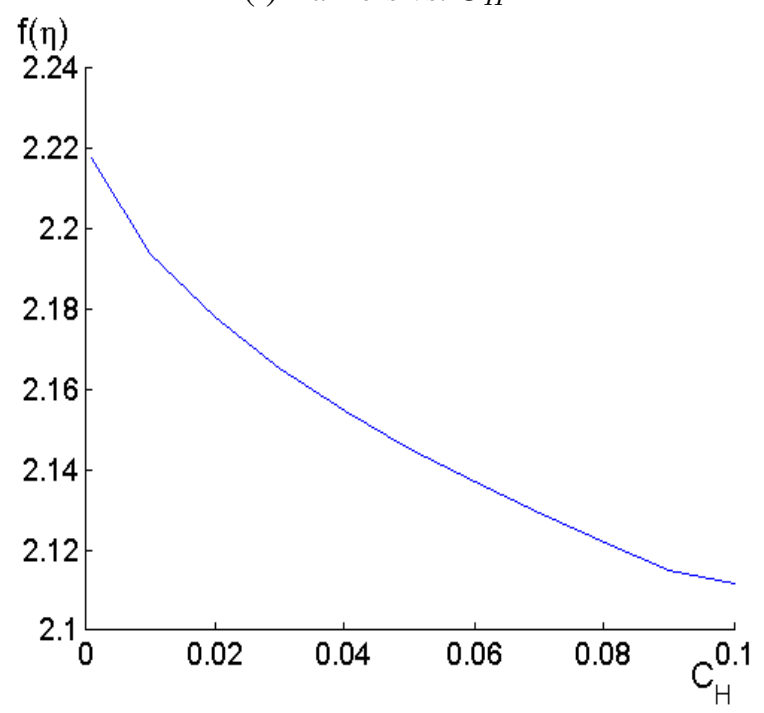

(iii) Value Function vs. $C_{H}$

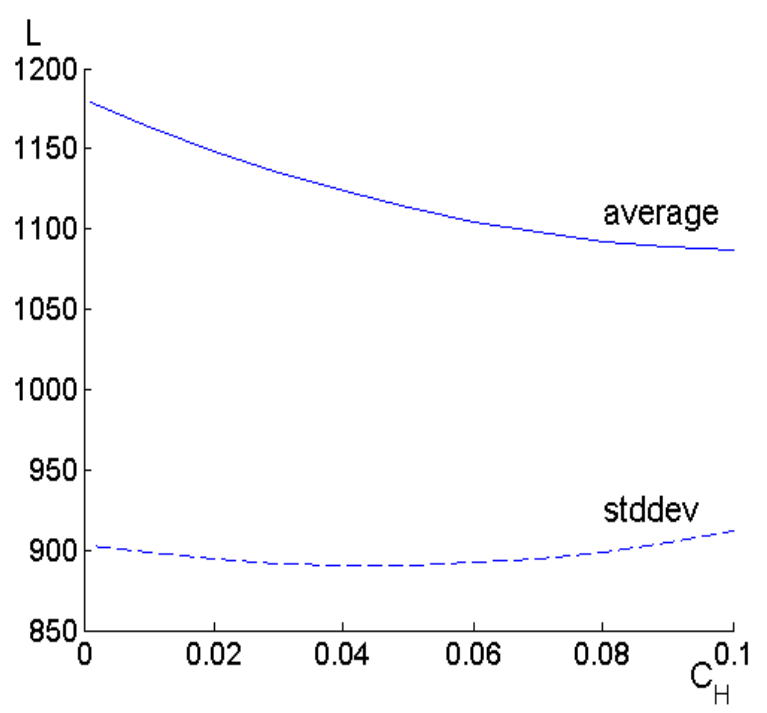

(ii) Labor Level vs. $C_{H}$

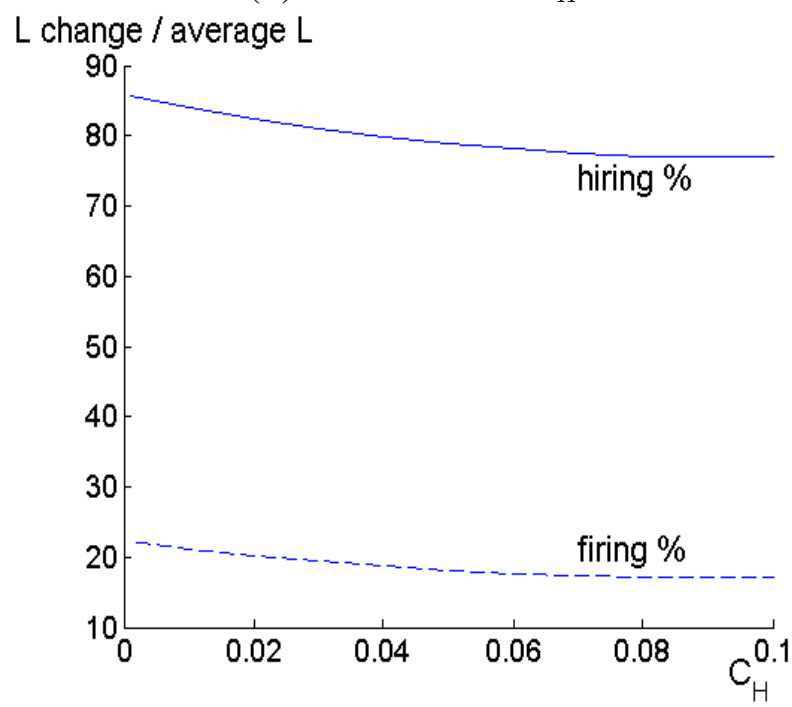

(iv) Hiring and Firing $\%$ vs. $C_{H}$

Figure 5: The effect of firm-sized hiring cost $C_{H}$ on optimal strategy $\left(b_{F}, \bar{u}_{F}, u_{H}, b_{H}\right)$, labor level $L$, value function $f(\eta)$, and on hiring and firing relative to the average labor level. The model parameters are in Table 2. Figures (ii) and (iv) are calculated by Monte Carlo Simulation with initial value $\eta_{0}=0.3$ and 120 time steps over a ten year time horizon. By Lemma 2.1, in Figures (i) and (ii) the corresponding no friction $\eta^{*} \approx 0.32$ and average no friction labor level average $\left(L^{*}\right)=\operatorname{average}(Z) \cdot \eta^{*} \approx 1168$. By Lemmas 2.1 and 2.2 , in Figure (iii) the corresponding value functions without labor market frictions and with high labor market frictions: $f_{N F}(0.3) \approx$ $2.34, f_{H F}(0.3) \approx 0.88$ 


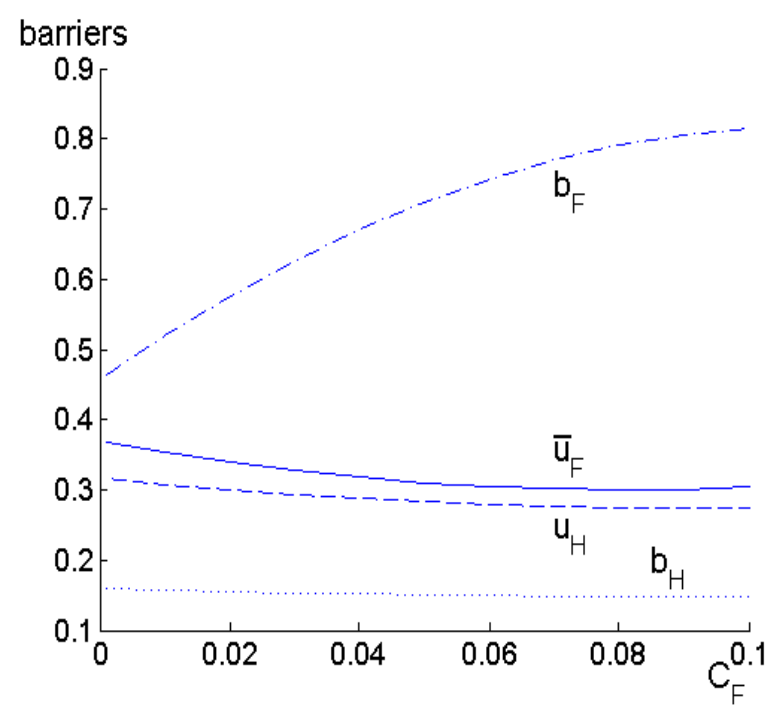

(i) Barriers vs. $C_{F}$

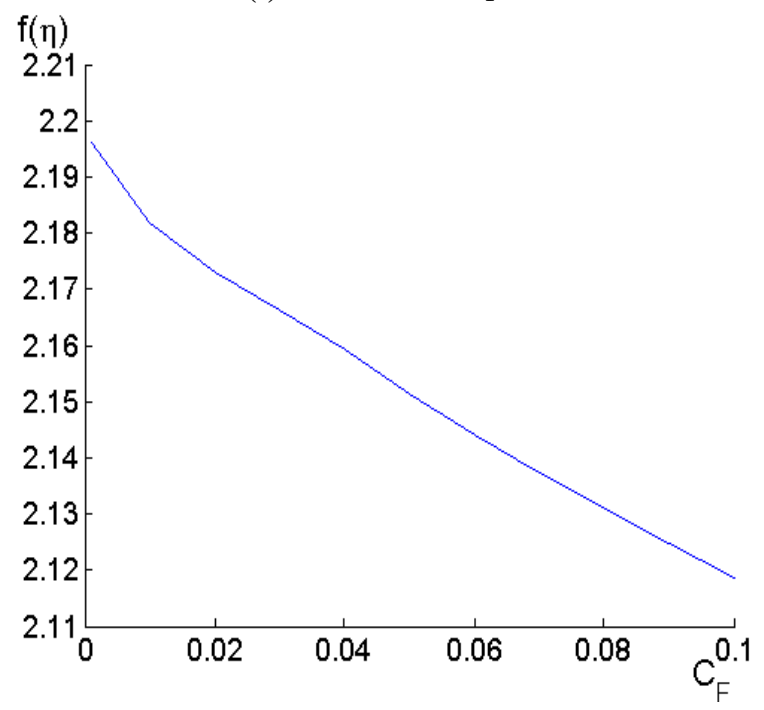

(iii) Value Function vs. $C_{F}$

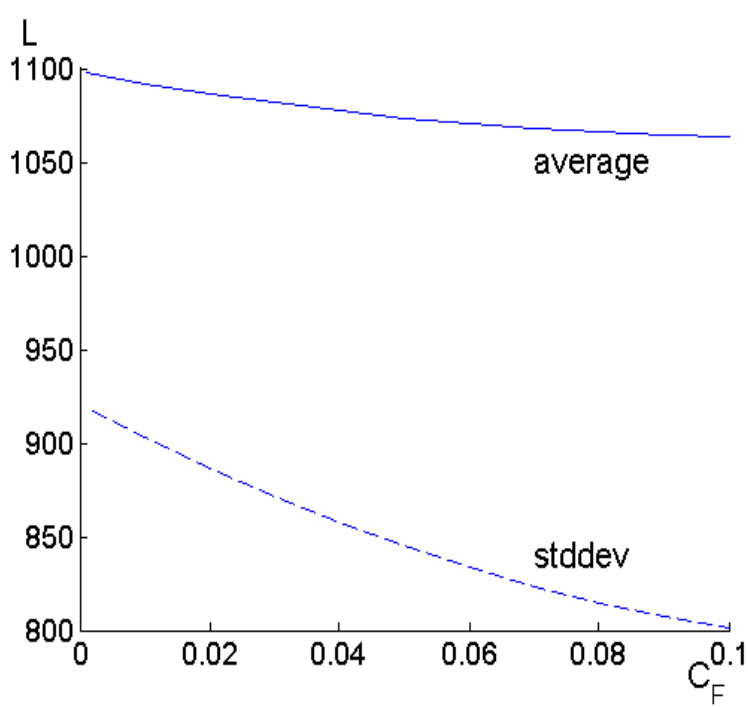

(ii) Labor Level vs. $C_{F}$

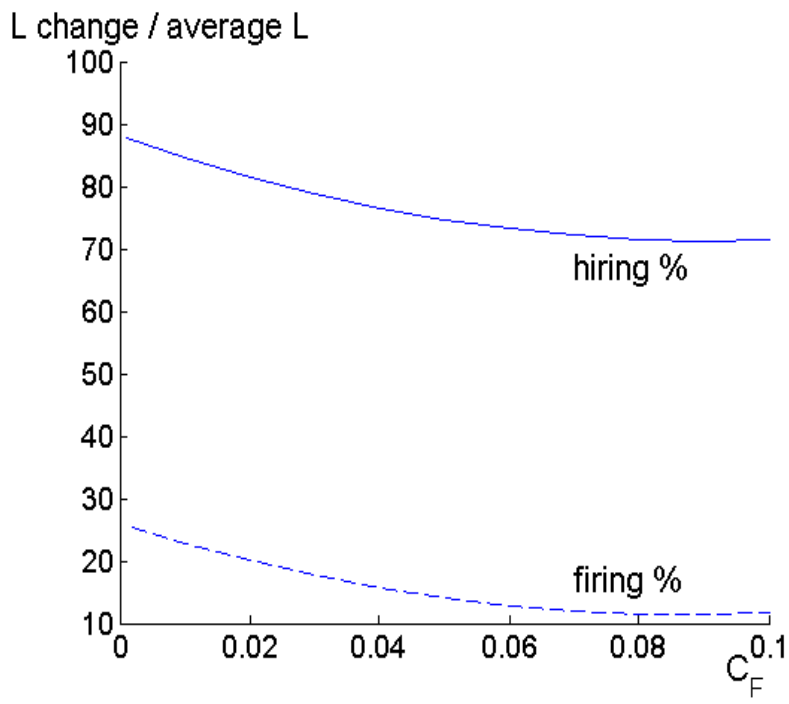

(iv) Hiring and Firing $\%$ vs. $C_{F}$

Figure 6: The effect of firm-sized firing cost $C_{F}$ on optimal strategy $\left(b_{F}, \bar{u}_{F}, u_{H}, b_{H}\right)$, labor level $L$, value function $f(\eta)$, and on hiring and firing relative to the average labor level. The model parameters are in Table 2. Figures (ii) and (iv) are calculated by Monte Carlo Simulation with initial value $\eta_{0}=0.3$ and 120 time steps over a ten year time horizon. By Lemma 2.1, in Figures (i) and (ii) the corresponding no friction $\eta^{*} \approx 0.32$ and average no friction labor level average $\left(L^{*}\right)=\operatorname{average}(Z) \cdot \eta^{*} \approx 1168$. By Lemmas 2.1 and 2.2 , in Figure (iii) the corresponding value functions without labor market frictions and with high labor market frictions: $f_{N F}(0.3) \approx$ $2.34, f_{H F}(0.3) \approx 0.88$ 
firing by about $0.58 \%$. Consistent with Proposition 2.5, when proportional hiring $\operatorname{cost} c_{H}$ rises, the hiring barriers and the difference between the barriers fall and the company hires less (Figures 7(i) and 7(iv)). Further, due to the higher proportional hiring costs, the firing barriers rise and this way the company decreases the number of employees fired and the need to hire in the future. In Figure 7 (ii) the average labor level falls substantially in the proportional hiring cost because then it is less profitable to replace the employees who quit or who have been fired. Under the baseline parameter values of Table 2, even when the proportional hiring cost is zero then the average labor level is significantly less than the corresponding average in the no friction case (the average labor levels are 1085 and 1168, respectively). By Figure 7(iii) and Proposition 2.3, the firm value naturally falls in $c_{H}$.

Similar to the case of proportional hiring cost, by Figure 8(i) and Proposition 2.5, the firing barriers $b_{F}$ and $u_{F}$ rise quickly in proportional firing cost $c_{F}$ and this decreases firing. Furthermore, both the hiring barriers $\left(b_{H}\right.$ and $\left.u_{H}\right)$ fall slightly due to the falling value of new hires and this decreases hiring in the future. Hence, we observe a decreasing hiring and firing percentages in Figure 8(iv). More specifically,

$E_{\text {hiring, proportional firing cost }}=-0.12 \quad$ and $\quad E_{\text {firing, proportional firing cost }}=-0.82$,

i.e., a one percent increase in the proportional firing cost decreases hiring by about $0.12 \%$ and firing by about $0.82 \%$. In Figure 8 (ii) the average labor level falls in the proportional firing cost because then the value of the employees fall. Under the baseline parameter values of Table 2 , even when the proportional firing cost is zero then the average labor level is significantly less than the corresponding average in the no friction case (the average labor levels are 1072 and 1168, respectively). As expected, the proportional firing cost decreases the value of the company (see Figure 8(iii) and Proposition 2.3.

By Figures 7 and 8 , the higher the proportional costs the lower the profitability and less likely the company hires and fires workers. This implies that in countries and states that have high proportional hiring or firing costs, there are low job reallocation rates. 


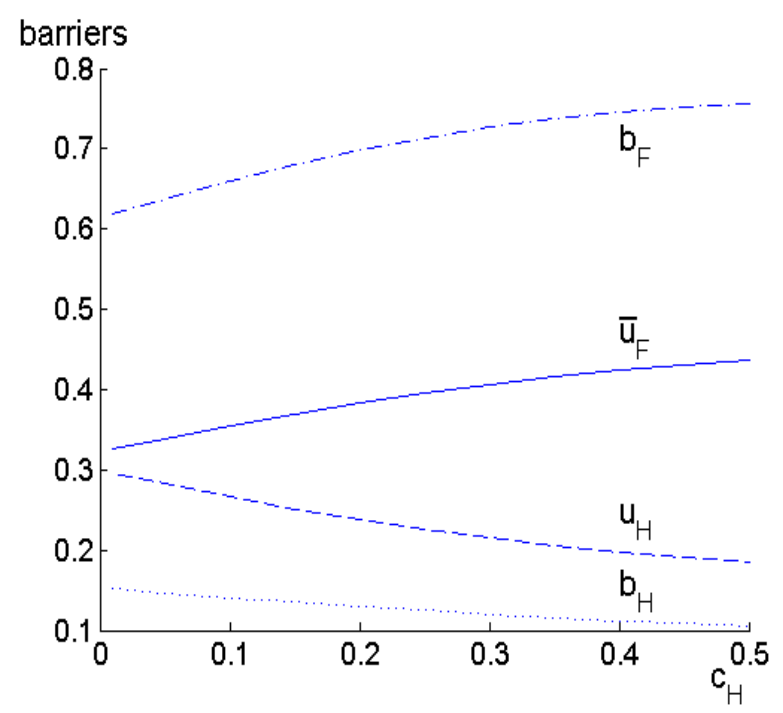

(i) Barriers vs. $c_{H}$

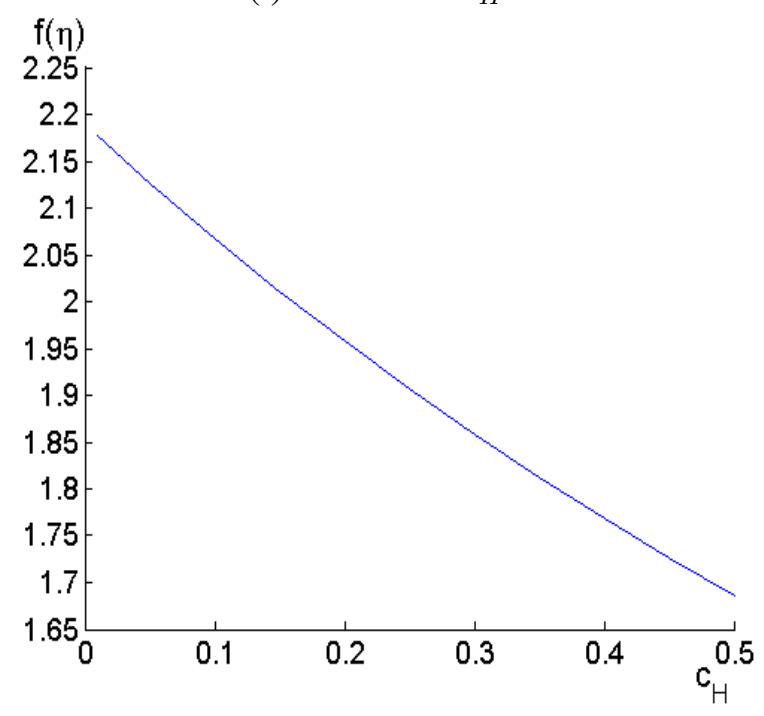

(iii) Value Function vs. $c_{H}$

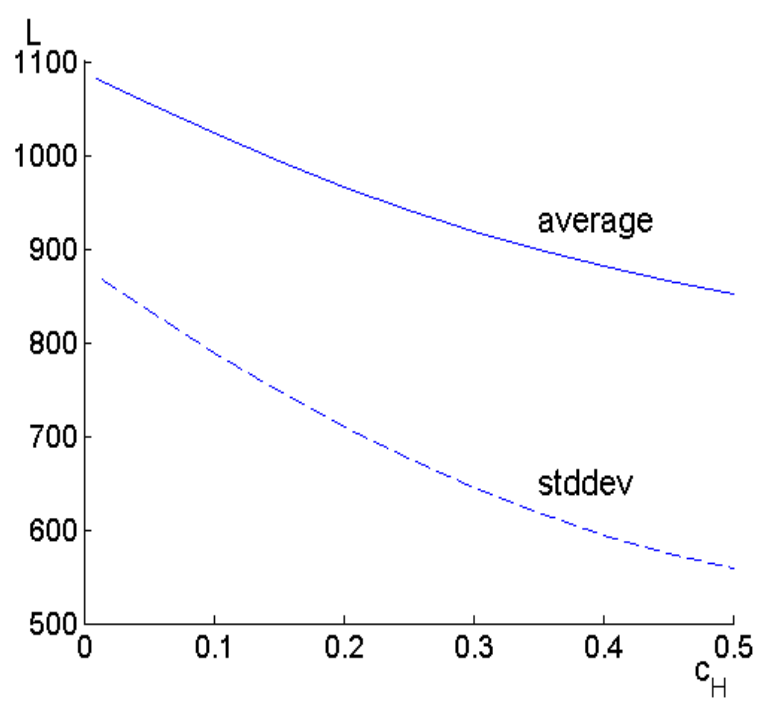

(ii) Labor Level vs. $c_{H}$

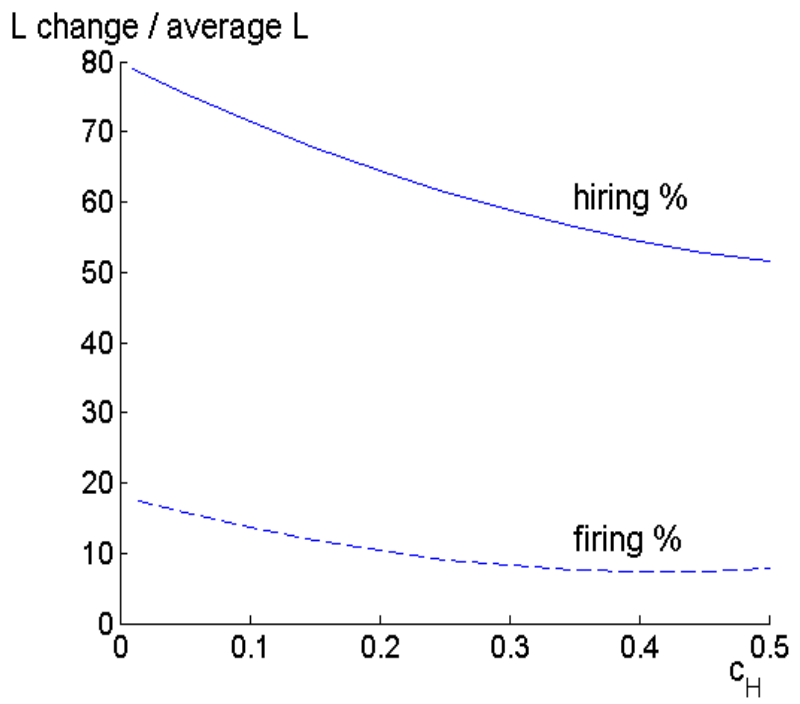

(iv) Hiring and Firing $\%$ vs. $c_{H}$

Figure 7: The effect of proportional hiring costs $c_{H}$ on optimal strategy $\left(b_{F}, \bar{u}_{F}, u_{H}, b_{H}\right)$, labor level $L$, value function $f(\eta)$, and on hiring and firing relative to the average labor level. The model parameters are in Table 2. Figures (ii) and (iv) are calculated by Monte Carlo Simulation with initial value $\eta_{0}=0.3$ and 120 time steps over a ten year time horizon. By Lemma 2.1, in Figures (i) and (ii) the corresponding no friction $\eta^{*} \approx 0.32$ and average no friction labor level average $\left(L^{*}\right)=\operatorname{average}(Z) \cdot \eta^{*} \approx 1168$. By Lemmas 2.1 and 2.2, in Figure (iii) the corresponding value functions without labor market frictions and with high labor market frictions: $f_{N F}(0.3) \approx 2.34, f_{H F}(0.3) \approx 0.88$. 


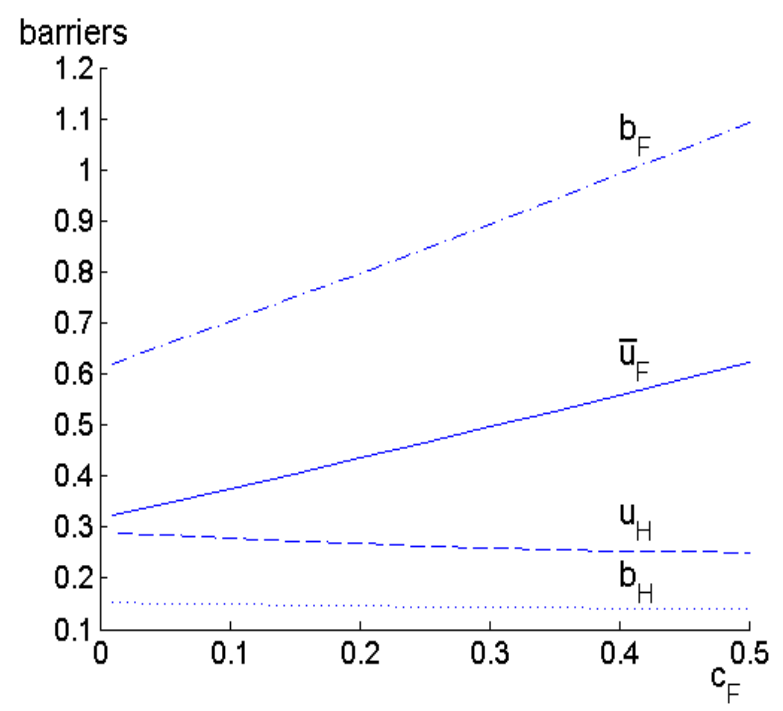

(i) Barriers vs. $c_{F}$

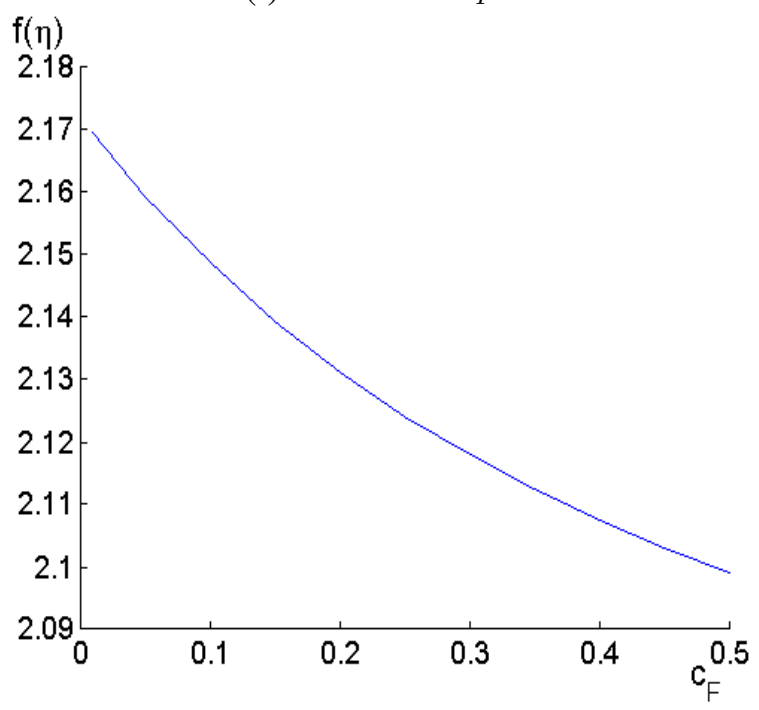

(iii) Value Function vs. $c_{F}$

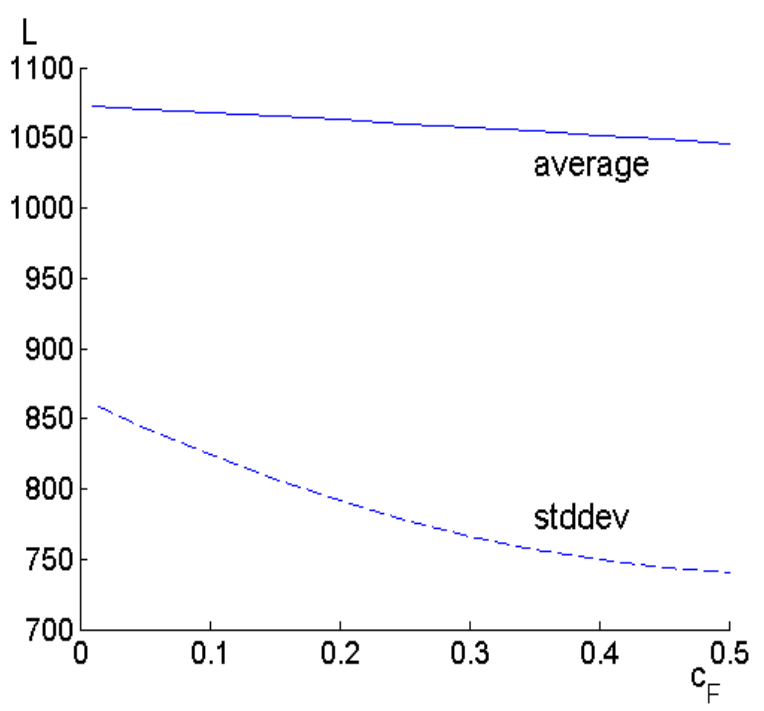

(ii) Labor Level vs. $c_{F}$

$\mathrm{L}$ change / average $\mathrm{L}$

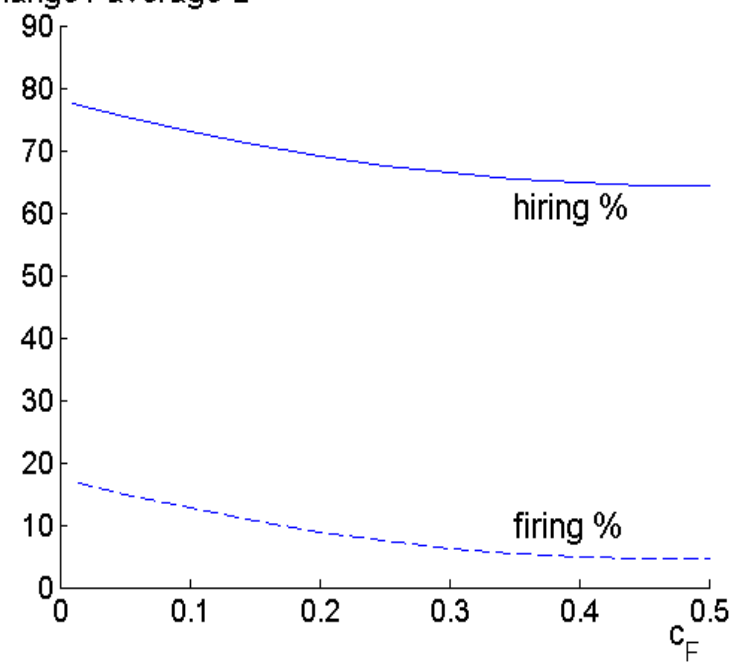

(iv) Hiring and Firing $\%$ vs. $c_{F}$

Figure 8: The effect of proportional firing costs $c_{F}$ on optimal strategy $\left(b_{F}, \bar{u}_{F}, u_{H}, b_{H}\right)$, labor level $L$, value function $f(\eta)$, and on hiring and firing relative to the average labor level. The model parameters are in Table 2. Figures (ii) and (iv) are calculated by Monte Carlo Simulation with initial value $\eta_{0}=0.3$ and 120 time steps over a ten year time horizon. By Lemma 2.1, in Figures (i) and (ii) the corresponding no friction $\eta^{*} \approx 0.32$ and average no friction labor level average $\left(L^{*}\right)=\operatorname{average}(Z) \cdot \eta^{*} \approx 1168$. By Lemmas 2.1 and 2.2, in Figure (iii) the corresponding value functions without labor market frictions and with high labor market fricitions: $f_{N F}(0.3) \approx 2.34, f_{H F}(0.3) \approx 0.88$. 


\section{Relocation option}

Let $\widehat{V}(Z, L)$ be the value function of the alternative location and it is given by Proposition 2.4 with the model parameters in that location. Let $\bar{V}(Z, L)$ be the value function of the old location that includes an option to relocate. Then from (7) and (8) we get

$$
\begin{aligned}
\bar{V}\left(Z_{0}, L_{0}\right)=\sup _{\tau \geq 0, \pi \in \Pi} E & {\left[\int_{0}^{\tau} e^{-r t}\left(Z_{t}^{1-\lambda}\left(A L_{t}\right)^{\lambda}-\omega L_{t}\right) d t\right.} \\
& -\sum_{i} e^{-r t_{i}^{\pi}} I_{\left\{s_{i}^{\pi}=H\right\}}\left(X_{i}^{\pi} c_{H}+C_{H} L_{t_{i}^{\pi}}\right) \\
& -\sum_{i} e^{-r\left(t_{i}^{\pi}+\Delta\right)} I_{\left\{s_{i}^{\pi}=F\right\}}\left(X_{i}^{\pi} c_{F}+C_{F} L_{t_{i}^{\pi}+\Delta}\right) \\
& \left.+e^{-r \tau}\left(\widehat{V}\left(Z_{\tau}, 0\right)-c_{F} L_{\tau}-C_{F} L_{\tau}-\Delta \omega L_{\tau}-R\right)\right],
\end{aligned}
$$

where $\tau$ is the relocation time, $R$ is the relocation cost, and the expected cash flows before $\tau$ are calculated by using the model parameters in the current location. The term $c_{F} L_{\tau}+C_{F} L_{\tau}+$ $\Delta \omega L_{\tau}+R$ in 21 is the relocation cost $R$ plus the firing cost in the old location including the salaries during the firing delay $\left(c_{F} L_{\tau}+C_{F} L_{\tau}+\Delta \omega L_{\tau}\right)$. Thus, 21) is the expected discounted revenues minus the wage, hiring and firing costs in the old location up to the relocation time plus the value in the alternative location minus all the costs due to the relocation. $\bar{V}(\cdot, \cdot)$ has similar properties as the value function without relocation option in Proposition 2.3 .

Proposition 4.1. (Value function properties) Assume that the parameters of the alternative location are fixed, i.e., the value function $\widehat{V}(\cdot, 0)$ is fixed. The value function $\bar{V}(\cdot, \cdot)$ defined in (21) has the following properties:

(i) $\bar{V}(\cdot, \cdot)$ is non-increasing in the current location's hiring and firing $\operatorname{costs} c_{H}, C_{H}, c_{F}$, and $C_{F}$ and in the current location's firing delay $\Delta$.

(ii) If $\Delta=C_{F}=C_{H}=0$ and $\widehat{V}(\cdot, 0)-R$ is concave, then $\bar{V}(\cdot, \cdot)$ is concave.

As in Proposition 2.3, the hiring and firing frictions do not help the firm and the value function may not be concave when one of $\Delta, C_{F}$, and $C_{H}$ is positive. We also have the following proposition that is similar to Proposition 2.4. 
Proposition 4.2. (Optimality) Assume that the firm value in the old location, $\bar{V}(Z, L)$, satisfies the regularity conditions of Ito's formula and that $\widehat{V}(Z, L)$ is given by Proposition 2.4 Then $\bar{V}(Z, L)$ has the following properties for all $Z>0, L>0$.

(i) Hiring is an option:

$$
\bar{V}(Z, L) \geq \sup _{x>0}\left[\bar{V}(Z, L+x)-c_{H} x\right]-C_{H} L
$$

(ii) Firing is an option with a delay of $\Delta$ :

$$
\bar{V}(Z, L) \geq \bar{U}(Z, L, 0)
$$

where $\bar{U}\left(Z_{s}, L_{s}, s\right)$ represents the expected discounted firing value at time $s \in[0, \Delta]$, i.e.,

$$
\begin{aligned}
\bar{U}\left(Z_{s}, L_{s}, s\right)= & E\left[\int_{s}^{\Delta} e^{-r(t-s)}\left(Z_{t}^{1-\lambda}\left(A L_{t}\right)^{\lambda}-\omega L_{t}\right) d t\right. \\
& \left.+e^{-r(\Delta-s)} \sup _{x \in\left[0, L_{\Delta}\right)}\left(\bar{V}\left(Z_{\Delta}, L_{\Delta}-x\right)-c_{F} x-C_{F} L_{\Delta}\right) \mid \mathcal{F}_{s}\right] .
\end{aligned}
$$

(iii) Relocation is an option:

$$
\bar{V}(Z, L) \geq \widehat{V}(Z, 0)-c_{F} L-C_{F} L-\Delta \omega L-R
$$

(iv) The value is expected to fall at least by the flow profit:

$$
\mathcal{L} \bar{V}(Z, L)+Z^{1-\lambda}(A L)^{\lambda}-\omega L \leq 0
$$

(v) One of the above inequalities is tight for any $Z>0$ and $L>0$, that is,

$$
\begin{aligned}
\max & \left\{\mathcal{L} \bar{V}(Z, L)+Z^{1-\lambda}(A L)^{\lambda}-\omega L\right. \\
& \sup _{x>0}\left[\bar{V}(Z, L+x)-c_{H} x-C_{H} L\right]-\bar{V}(Z, L), \bar{U}(Z, L, 0)-\bar{V}(Z, L), \\
& \left.\widehat{V}(Z, 0)-\bar{V}(Z, L)-c_{F} L-C_{F} L-\Delta \omega L-R\right\}=0 .
\end{aligned}
$$


Assume $\widehat{R} \equiv \frac{R}{Z}$ is a constant. This allows us to make the following transformations

$$
\eta=\frac{L}{Z}, \bar{f}(\eta)=\frac{\bar{V}(Z, L)}{Z}, \widehat{f}(\eta)=\frac{\widehat{V}(Z, L)}{Z}, \bar{g}(\eta, s)=\frac{\bar{U}(Z, L, s)}{Z}
$$

Then (27) can be reduced to

$$
\begin{aligned}
\max & \left\{\mathcal{A} \bar{f}+(A \eta)^{\lambda}-\omega \eta, \sup _{m>0}\left[\bar{f}(\eta+m)-c_{H} m\right]-C_{H} \eta-\bar{f}(\eta),\right. \\
& \left.\bar{g}(\eta, 0)-\bar{f}(\eta), \widehat{f}(0)-c_{F} \eta-C_{F} \eta-\Delta \omega \eta-\widehat{R}-\bar{f}(\eta)\right\}=0 \text { for } \eta>0
\end{aligned}
$$

and

$$
\left\{\begin{array}{l}
\bar{g}_{s}+\mathcal{A} \bar{g}+(A \eta)^{\lambda}-\omega \eta=0 \text { for } \eta>0 \text { and } s \in[0, \Delta) \\
\bar{g}(\eta, \Delta)=\sup _{m \in[0, \eta)}\left[\bar{f}(\eta-m)-c_{F} m\right]-C_{F} \eta
\end{array}\right.
$$

Define the relocation domain as follows

$$
\mathbf{R R}=\left\{\eta \in(0,+\infty): \bar{f}(\eta)=\widehat{f}(0)-c_{F} \eta-C_{F} \eta-\Delta \omega \eta-\widehat{R}\right\}
$$

Given appropriate model parameter values, we find numerically $\eta^{*}$ such that

$$
\mathbf{R R}=\left\{\eta \in(0,+\infty): \eta \leq \eta^{*}\right\}
$$

That is, if the ratio of labor to the demand and productivity risk factor falls below critical value $\eta^{*}$ then it is optimal to relocate to the alternative location. However, as we will see in the next section, it could be that $\eta^{*}<b_{H}$ and then the company never relocates.

\section{Comparative statics with the relocation option}

In this section we analyze the impact of different model parameters on the optimal hiring, firing, and relocation policy in the current location and on the value of the firm. We use the parameters in Table 2 for the current location, and the alternative location has the same parameters except the firing delay $\Delta$ is just few days ( 0.01 year). That is, in the alternative location there is no 
regulatory firing delay. By Figure 1, this corresponds to a situation where a company that sells its products in a global market and is currently located in Europe optimizes its hiring and firing policy as well as its relocation timing to US.

More specifically, below we analyze the effects of different labor market frictions in the current location similarly as in Section 3 , the parameters in the alternative location are constant. Note that, as discussed before, the realized target level $u_{F}(\eta)$ might be different from the expected target level $\bar{u}_{F}$ presented in the figures. Therefore, the realized firing quantity is not $b_{F}-\bar{u}_{F}$. Further, we do not analyze the effect of relocation cost $\widehat{R}$ because under the baseline parameters the company does not relocate even if $\widehat{R}$ equals zero. In all the cases analyzed in this section, we use $\widehat{R}=0.1$. Under the baseline parameter values, $\widehat{R}$ equals two-thirds of the wages during the firing delay and, by (25), the total relocation cost in the $\eta$-space of (28):

$$
\left(c_{F}+C_{F}+\Delta \omega\right) \eta+\widehat{R}=(0.018+0.025+0.5 \cdot 1) \cdot 0.3+0.1=0.263
$$

Thus, under the baseline parameter values, the main relocation cost is due to the firing regulatory delay.

\subsection{Firing delay}

First, we analyze the effects of firing regulatory delay in the current location. By Figures 3 a and 9a. under the baseline parameter values the relocation barrier is below the hiring barrier $b_{H}$ and, thus, there is no relocation even under one year firing delay (note that Figures $3 a$ (i) and $9 a$ (i) have different $y$-axis scales). This means that the relocation option does not have any value in this case and Figures $3 \mathrm{a}$ (ii) and (iii) apply here as well.

By (20), we calculate the firing and firing elasticities:

$$
E_{\text {hiring,firing delay }}=-0.03 \quad \text { and } \quad E_{\text {firing,firing delay }}=-0.12 .
$$

Because there is no relocation, these elasticities are the same as without the relocation option in 
(20). Further, we calculate the following elasticity for relocation:

$$
E_{\text {relocation,firing delay }}=\text { average }\left\{\frac{d\left(\frac{\text { relocation quantity }}{\text { labor level }}\right) / \frac{\text { relocation quantity }}{\text { labor level }}}{d(\text { firing delay }) / \text { firing delay }}\right\}=\frac{0}{0} \text {, }
$$

where the average is over the values in Figure 9 a (ii) and relocation quantity is the number of employees fired due to relocation. Since there is no relocation, the relocation elasticity is not defined. However, by using (29), we calculate the relocation elasticity also for other cases in this section.

When the productivity and demand uncertainty is doubled then the optimal policy changes substantially as shown in Figures $3 b$ and $9 b$. In this case, for all the firing delay values there is only relocation; if the company starts firing in the current location then it fires all the workers and starts operating in the alternative location according to the optimal policy there. Thus, the company only waits for the optimal relocation time. This optimal relocation time corresponds to the exercise time of an American option (see e.g. Duffie (2001)). When the uncertainty in the future payoff of an American option rises, it is optimal to wait and exercise the option later. Similarly with the relocation option, when the firing delay rises, the uncertainty in the relocation value is higher and, therefore, the company prefers to operate longer in the current location (without hiring there). This is the reason why $b_{F}$ and the difference between $b_{F}$ and the relocation barrier rise in $\Delta$ in Figure $9 \mathrm{~b}(\mathrm{i})$. Thus, companies that operate under long firing regulatory delays and that have stopped hiring might be just waiting for the optimal time to relocate.

By (20) and (29), the elasticities in this case are as follows:

$E_{\text {hiring,firing delay }}=\frac{0}{0}, \quad E_{\text {firing,firing delay }}=\frac{0}{0}, \quad$ and $\quad E_{\text {relocation,firing delay }}=-0.20$.

Since there is no hiring and firing in this case, the hiring and firing elasticities are not defined. However, rising the firing delay decreases firing due to relocation (but does not increase hiring or firing before the relocation) and the absolute value of the relocation elasticity is greater than the sum of hiring and firing elasticities without the relocation option.

When the delay is one year the relocation option raises the firm value about $9 \%$, so the benefit of the relocation is substantial. Thus, companies that operate under long regulatory firing delays 


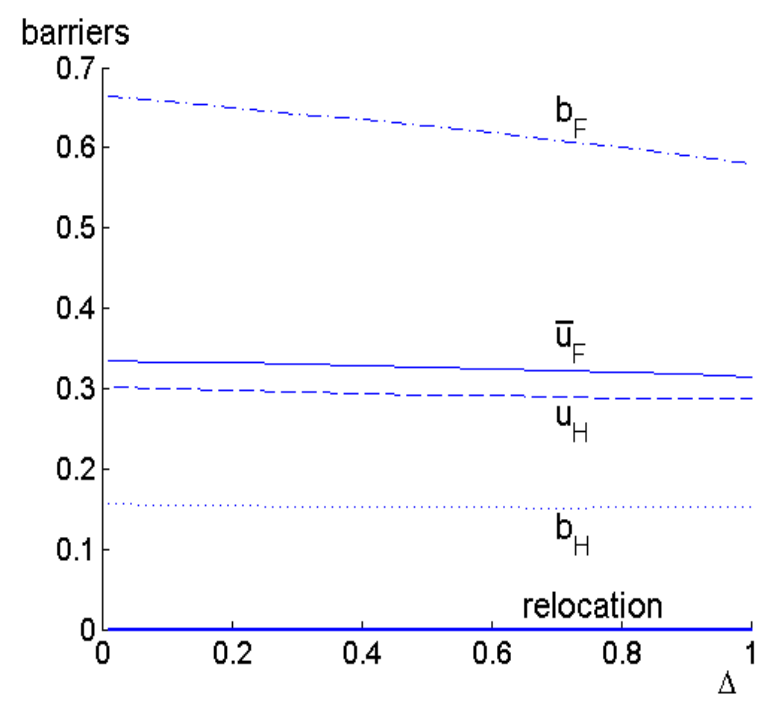

(i) Barriers vs. Delay

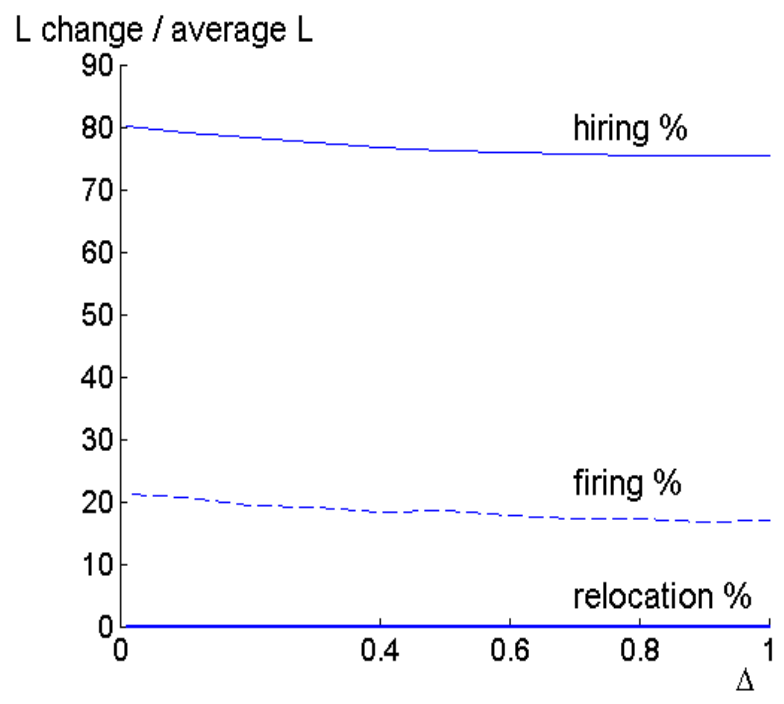

(ii) Hiring and Firing \% vs. Delay

Figure 9a: The effect of firing delay $\Delta$ in the current location on optimal strategy $\left(b_{F}, \bar{u}_{F}, u_{H}, b_{H}\right)$ and hiring and firing relative to the average labor level before relocation and at the relocation time with the baseline demand and productivity volatility $\sigma$. Compare with Figures $3 \mathrm{a}(\mathrm{i})$ and (iv). The model parameters in the current and alternative locations are in Table 2, except in the alternative location firing delay $\Delta=0.01$. The relocation cost $\widehat{R}=0.1$. Figure (ii) is calculated by Monte Carlo Simulation with initial value $\eta_{0}=0.3$ and 120 time steps over a ten year time horizon. In Figure (ii) "relocation" is firing in the current location when relocated and "firing" is firing in the current location when location is not changed.

and that have high demand or productivity uncertainty have high incentive to relocate. This suggests that in countries or states with long firing delays the fraction of companies that have low demand and productivity uncertainty is higher. Further, since the low uncertainty firms hire and fire less, the countries and states with long regulatory firing delays have less reallocation of labor between companies.

\subsection{Demand and productivity uncertainty}

Figure 10 illustrates the effects of the demand and productivity uncertainty in the current location. As expected, by Figure 10(iii), the uncertainty decreases the value of the firm. However, when comparing with Figure 4, we see that the relocation option gives a hedge against the high uncertainty because the value never goes under the relocation value. Thus, at high uncertainty 


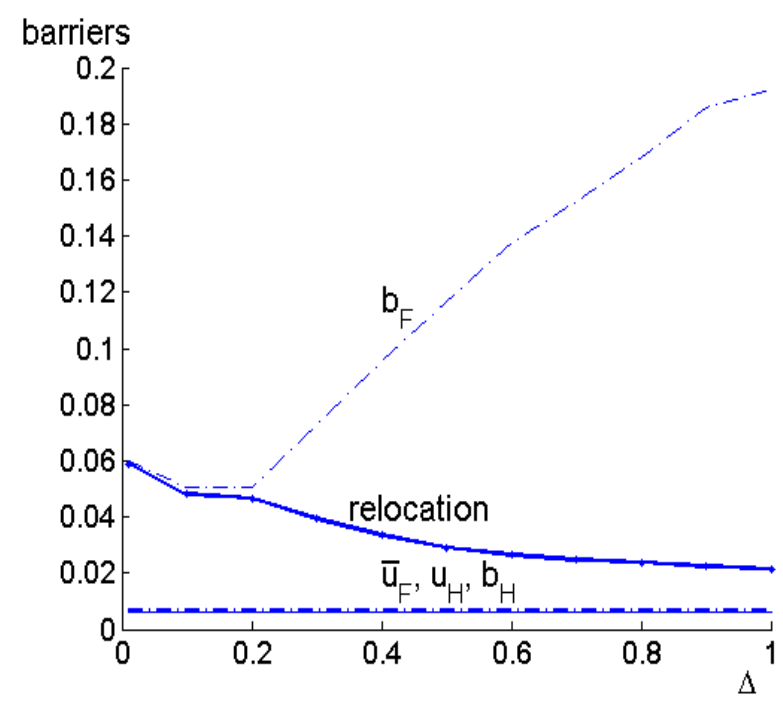

(i) Barriers vs. Delay

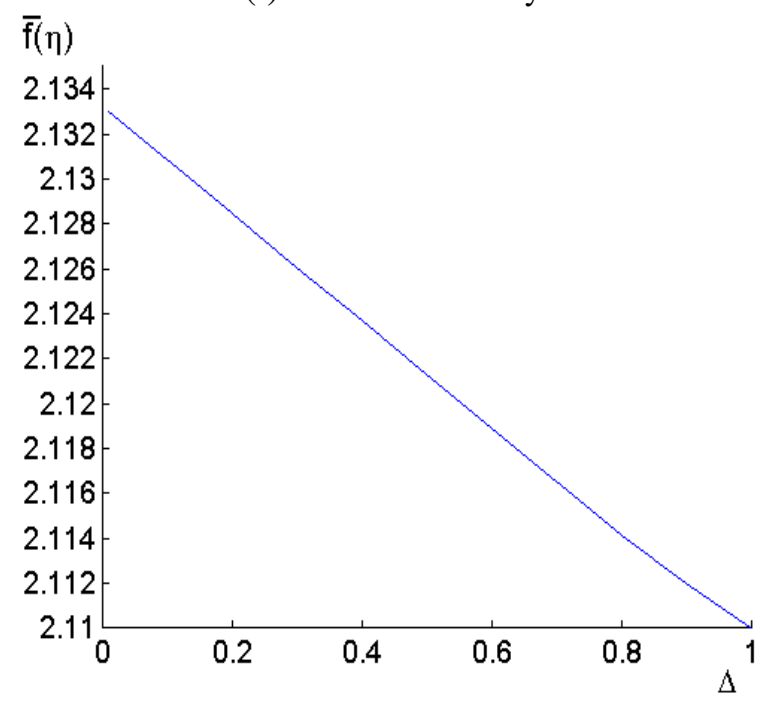

(iii) Value Function vs. Delay

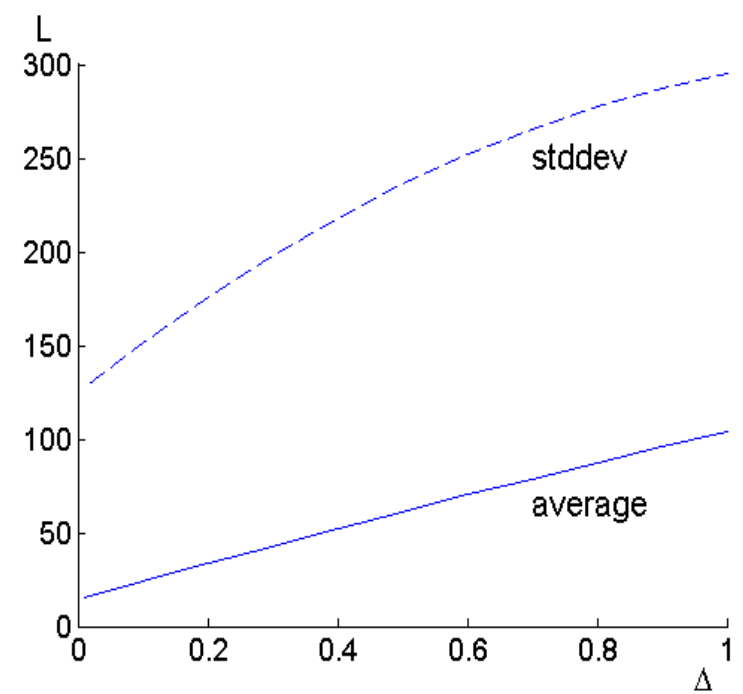

(ii) Labor Level vs. Delay

$\mathrm{L}$ change / average $\mathrm{L}$

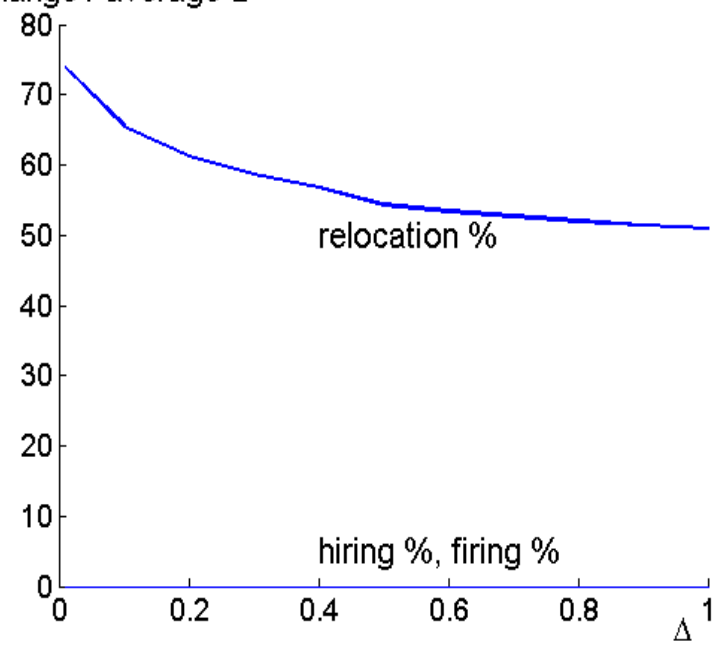

(iv) Hiring and Firing $\%$ vs. Delay

Figure 9b: The effect of firing delay $\Delta$ in the current location on optimal strategy $\left(b_{F}, \bar{u}_{F}, u_{H}, b_{H}\right)$, labor level $L$, value function $\bar{f}(\eta)$, and on hiring and firing relative to the average labor level before relocation and at the relocation time with high demand and productivity volatility, $\sigma=80 \%$, in the current location. Compare with Figure 3b. The model parameters in the current and alternative locations are in Table 2, except in the alternative location firing delay $\Delta=0.01$. The relocation cost $\widehat{R}=0.1$. Figures (ii) and (iv) are calculated by Monte Carlo Simulation with initial value $\eta_{0}=0.3$ and 120 time steps over a ten year time horizon. In Figure (iv) "relocation" is firing in the current location when relocated and "firing" is firing in the current location when location is not changed. 
levels relocation becomes more likely, there is no hiring before relocation, and the policy differs substantially from the case without the relocation option in Figure 4.

The elasticities in this case are as follows:

$$
E_{\text {hiring,volatility }}=-0.56, \quad E_{\text {firing,volatility }}=0, \quad \text { and } \quad E_{\text {relocation,volatility }}=1.41
$$

In this case, a one percent increase in the volatility decreases hiring by $0.56 \%$ and firing before relocation is unchanged because firing due to relocation increases $1.41 \%$.

\subsection{Firm-sized hiring and firing costs}

By Figures 5 and 11, the firm-sized hiring cost $C_{H}$ in the current location has substantial impact on the optimal policy. When $C_{H}$ is higher than 0.07 , there is no hiring, most likely only relocation, i.e., firing all the employees in the current location and moving the operations to the alternative location. This is because the hiring cost does not affect the total relocation cost in (25) but it decreases the value of operations in the current location. Thus, when $C_{H}$ is high, the relocation is done earlier. Note that even under high hiring costs the firm might decide to fire some of the workers, not all of them. Thus, as discussed before, the realized target level $u_{F}(\eta)$ might be different from $\bar{u}_{F}$.

The elasticities of the firm-sized hiring cost are as follows:

$E_{\text {hiring, firm-sized hiring cost }}=-0.77, \quad E_{\text {firing, firm-sized hiring cost }}=-0.11, \quad$ and $E_{\text {relocation, firm-sized hiring cost }}=1.81$,

i.e., the firm-sized cost decreases hiring and firing before relocation and raises substantially firing due to relocation. Further, under the relocation option the absolute value of hiring elasticity is higher than the corresponding number without the option.

According to Figures 6 and 12 , the firm-sized firing cost $C_{F}$ in the current location affects the relocation decision only at high cost values. This is because the firing cost raises also the total relocation cost in 25) and this way the value of relocation falls. However, there is no hiring 


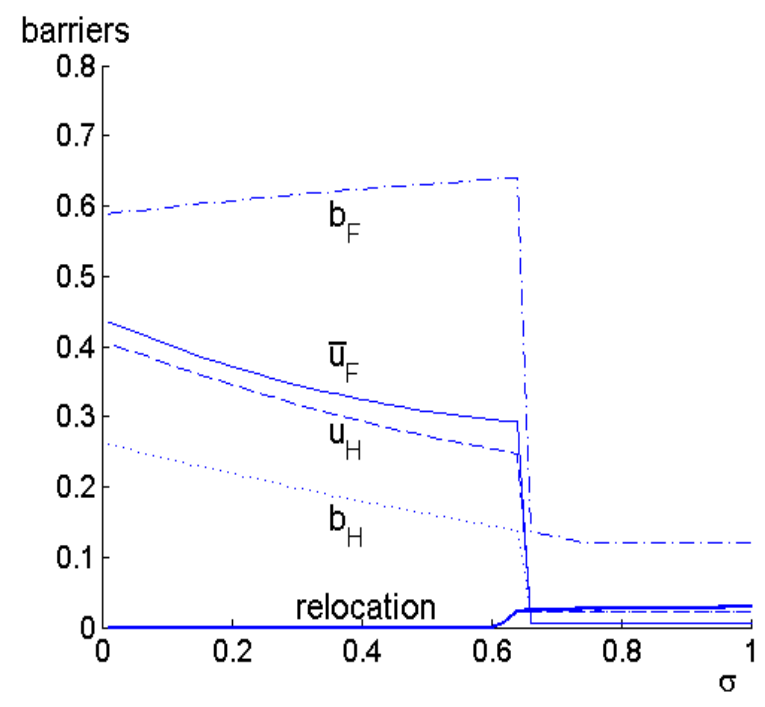

(i) Barriers vs. Volatility

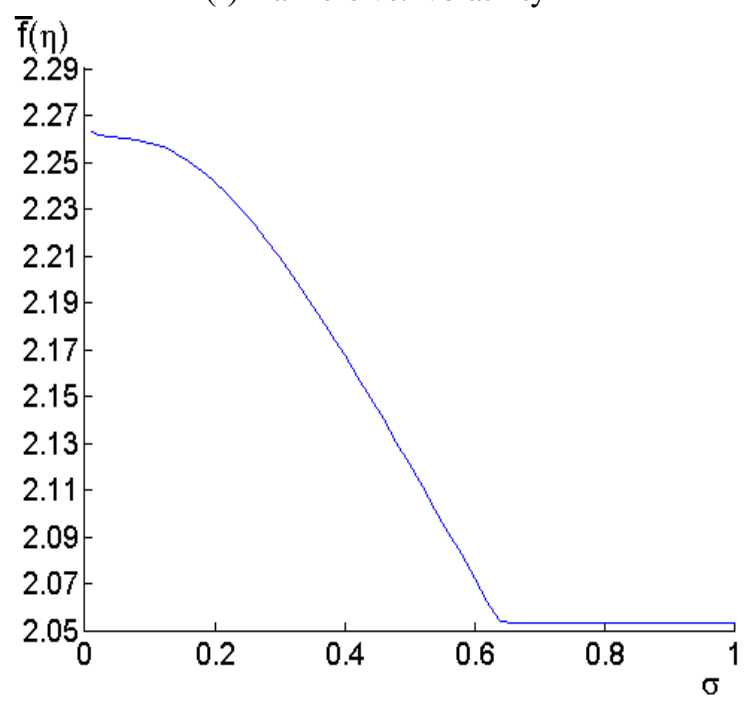

(iii) Value Function vs. Volatility

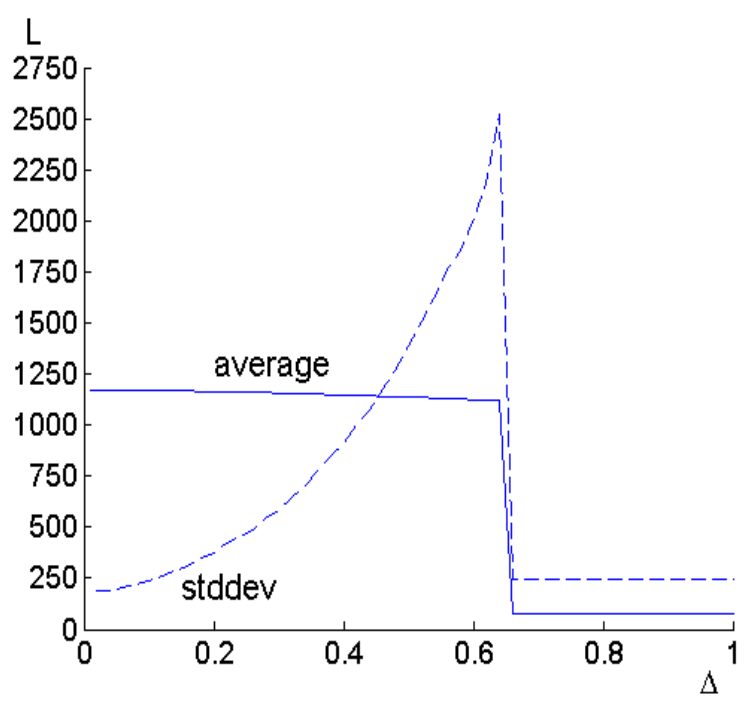

(ii) Labor Level vs. Volatility

$\mathrm{L}$ change / average L

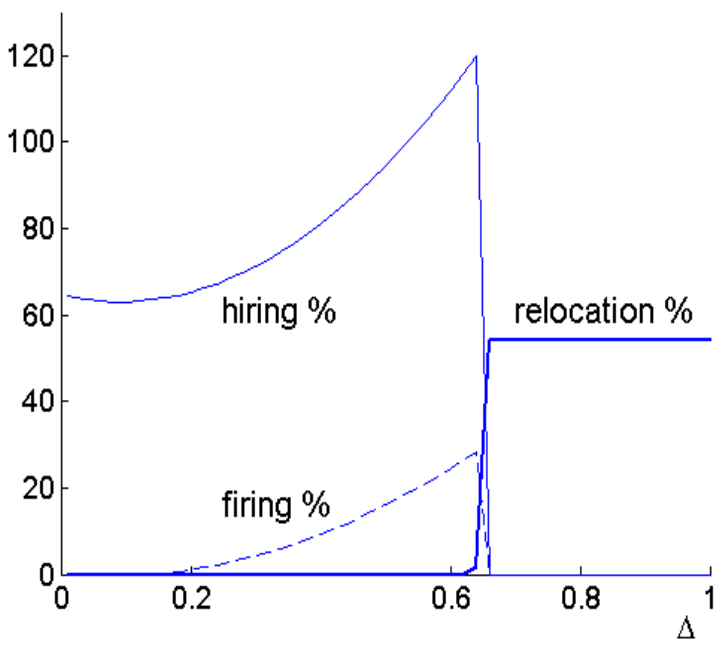

(iv) Hiring and Firing \% vs. Volatility

Figure 10: The effect of demand and productivity volatility $\sigma$ in the current location on optimal strategy $\left(b_{F}, \bar{u}_{F}, u_{H}, b_{H}\right)$, labor level $L$, value function $\bar{f}(\eta)$, and on hiring and firing relative to the average labor level before relocation and at the relocation time. Compare with Figure 4. The model parameters in the current and alternative locations are in Table 2, except in the alternative location firing delay $\Delta=0.01$. The relocation cost $\widehat{R}=0.1$. Figures (ii) and (iv) are calculated by Monte Carlo Simulation with initial value $\eta_{0}=0.3$ and 120 time steps over a ten year time horizon. In Figure (iv) "relocation" is firing in the current location when relocated and "firing" is firing in the current location when location is not changed. 
when $C_{F}>0.8$. The elasticities in this case are as follows:

$$
\begin{aligned}
& E_{\text {hiring, firm-sized firing cost }}=-0.77, \quad E_{\text {firing, firm-sized firing cost }}=-0.70, \quad \text { and } \\
& E_{\text {relocation, firm-sized firing cost }}=4.15 .
\end{aligned}
$$

Thus, as with the firm-sized hiring cost, the firm-sized firing cost decreases hiring and firing before relocation and raises substantially firing due to relocation. Further, the absolute values of hiring and firing elasticities are higher than the corresponding numbers without the relocation option.

\subsection{Proportional hiring and firing costs}

As with the firm-sized hiring cost, the proportional hiring cost $c_{H}$ in the current location has substantial impact on the relocation policy as shown in Figures 7 and 13 . When $c_{H}>0.1$ there is no hiring, mostly likely just firing due to relocation. This is because the hiring cost does not affect the total relocation cost in 25 but it decreases the value of operations in the current location. Thus, then the relocation is done earlier. As with the firm-sized hiring cost, the firm value is hedged by the relocation option. Further, even under high proportional hiring costs the firm might decide to fire some of the workers, not all of them. Thus, as discussed before, the realized target level $u_{F}(\eta)$ might be different from $\bar{u}_{F}$.

The elasticities of the proportional hiring cost are as follows:

$E_{\text {hiring, proportional hiring cost }}=-3.97, \quad E_{\text {firing, proportional hiring cost }}=-0.18, \quad$ and $E_{\text {relocation, proportional hiring cost }}=0.59$,

i.e., the proportional hiring cost decreases hiring and firing before relocation and raises firing due to relocation. Further, hiring is more elastic in this case than under the firm-sized costs in subsection 5.3 and without the relocation option in Section 3 .

As with the firm-sized firing cost, by Figures 8 and 14 , the proportional firing $\operatorname{cost} c_{F}$ in the current location affects the relocation decision only at high values. This is because the firing cost raises also the total relocation cost in 25 and this way the value of relocation falls. However, 


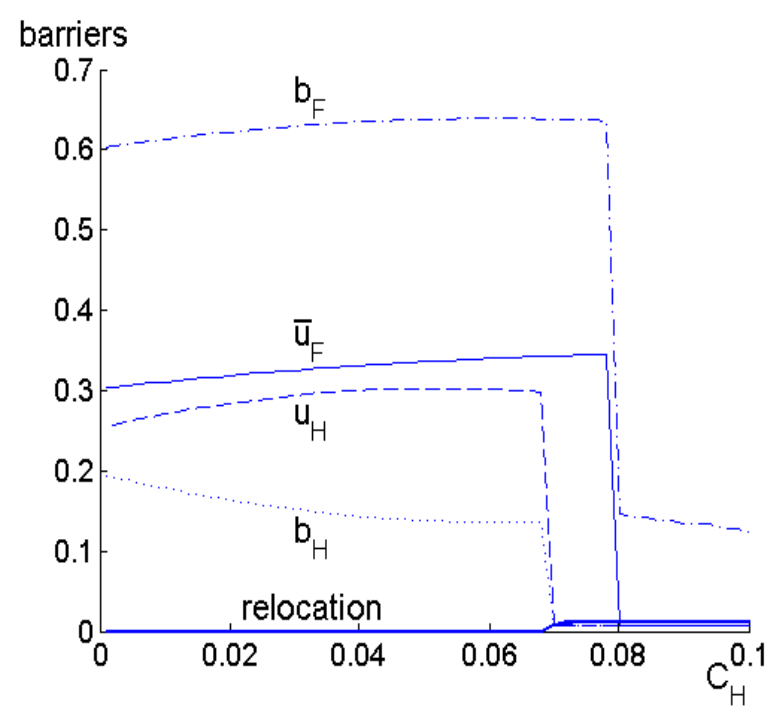

(i) Barriers vs. $C_{H}$

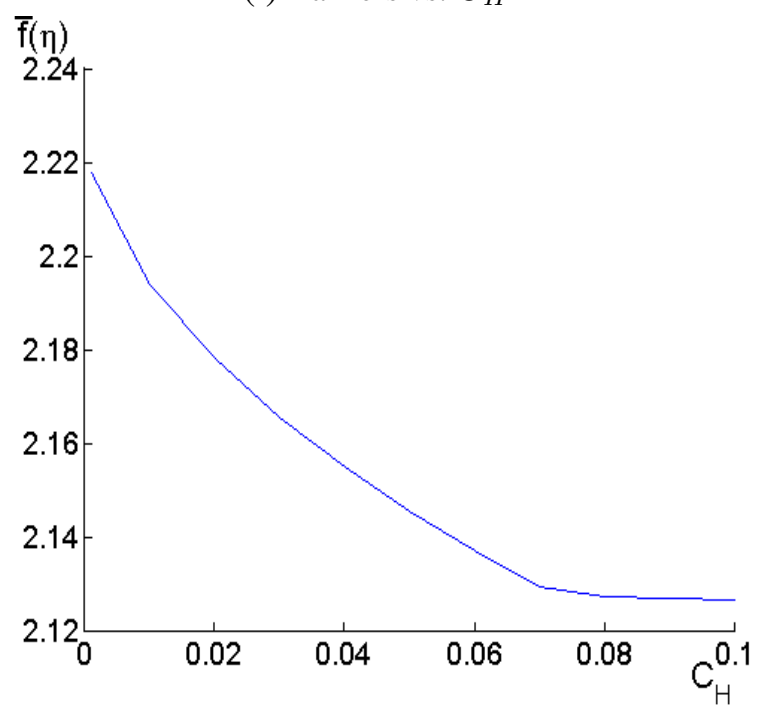

(iii) Value Function vs. $C_{H}$

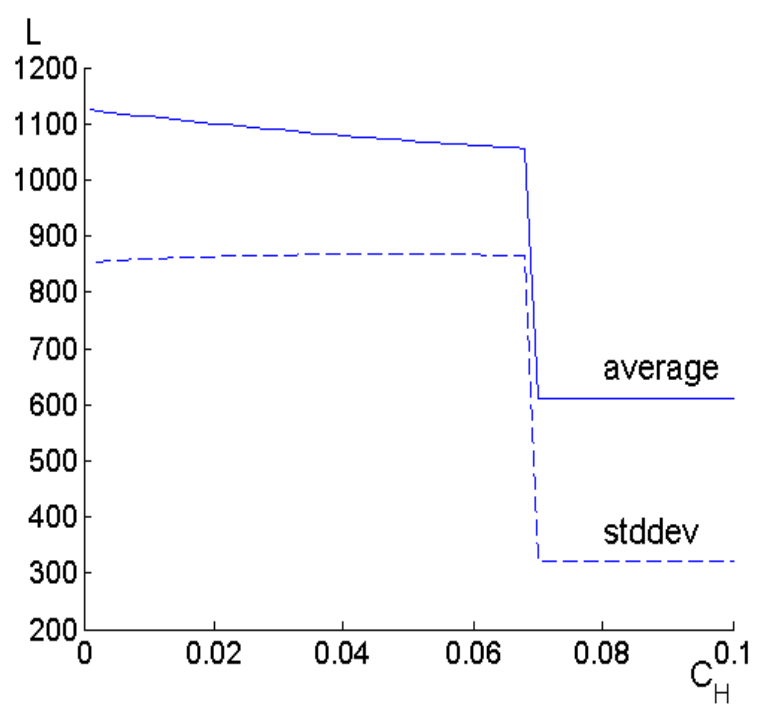

(ii) Labor Level vs. $C_{H}$

$\mathrm{L}$ change / average $\mathrm{L}$

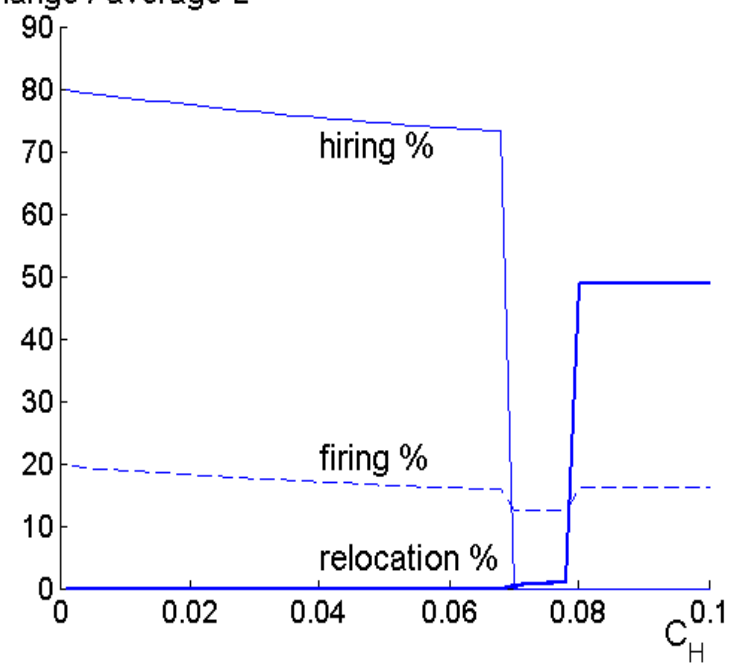

(iv) Hiring and Firing $\%$ vs. $C_{H}$

Figure 11: The effect of firm-sized hiring $\operatorname{cost} C_{H}$ in the current location on optimal strategy $\left(b_{F}, \bar{u}_{F}, u_{H}, b_{H}\right)$, labor level $L$, value function $\bar{f}(\eta)$, and on hiring and firing relative to the average labor level before relocation and at the relocation time. Compare with Figure 5. The model parameters in the current and alternative locations are in Table 2, except in the alternative location firing delay $\Delta=0.01$. The relocation cost $\widehat{R}=0.1$. Figures (ii) and (iv) are calculated by Monte Carlo Simulation with initial value $\eta_{0}=0.3$ and 120 time steps over a ten year time horizon. In Figure (iv) "relocation" is firing in the current location when relocated and "firing" is firing in the current location when location is not changed. 


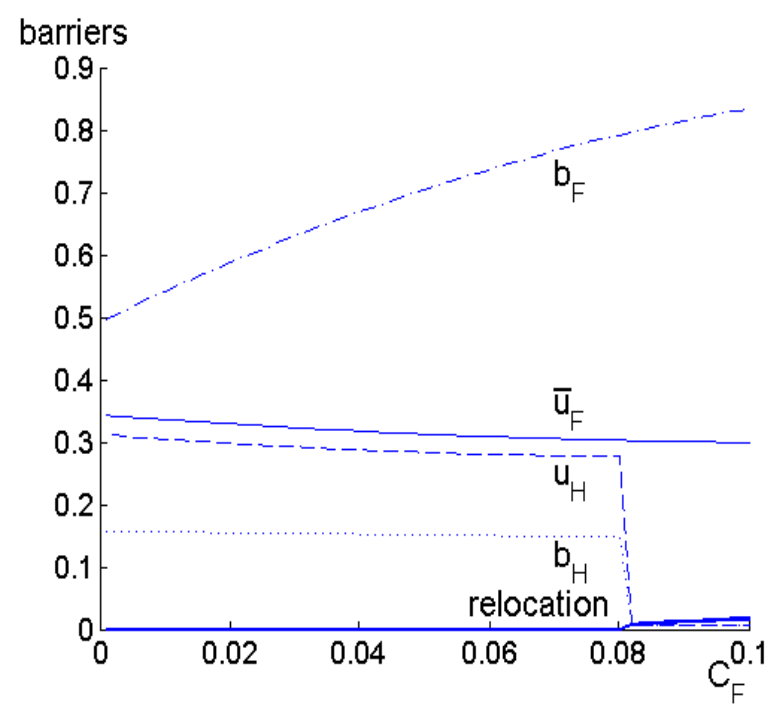

(i) Barriers vs. $C_{F}$

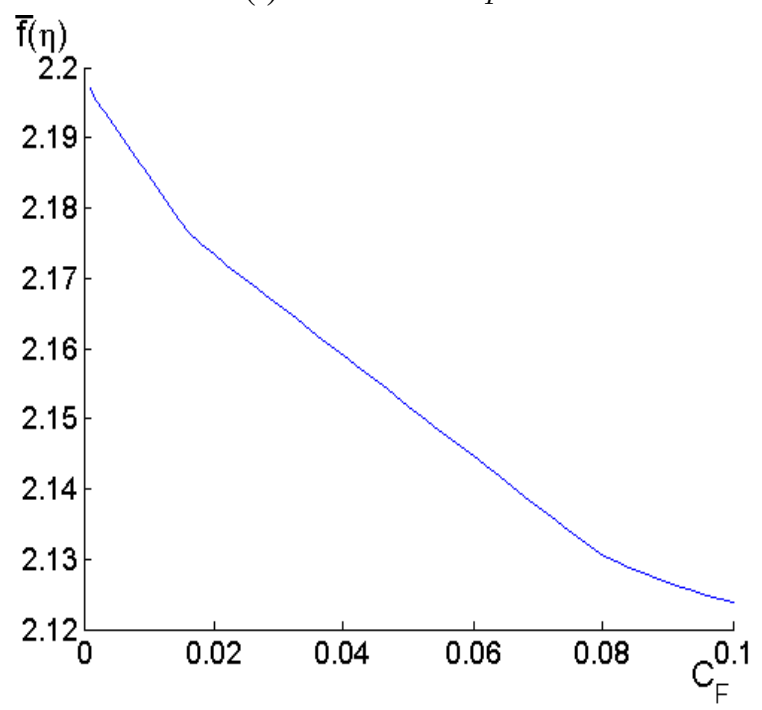

(iii) Value Function vs. $C_{F}$

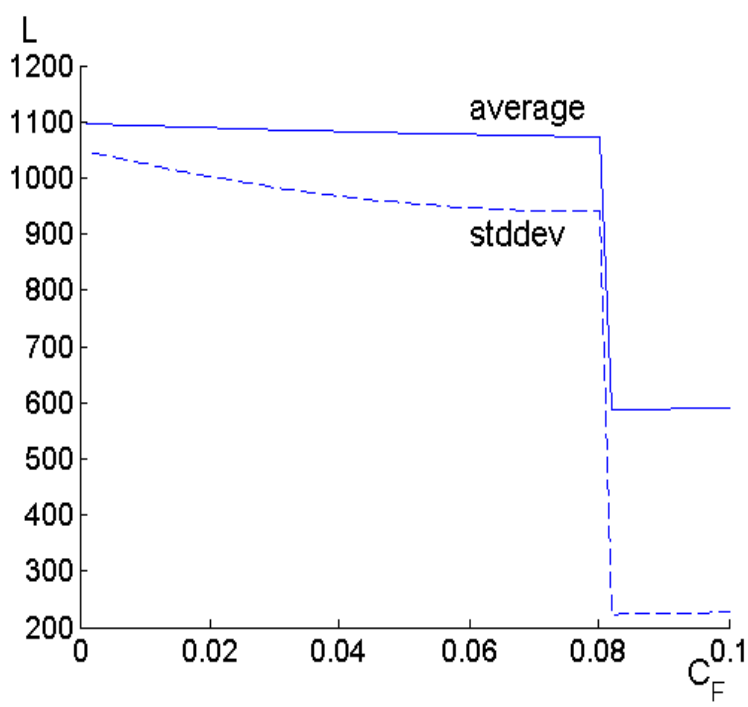

(ii) Labor Level vs. $C_{F}$

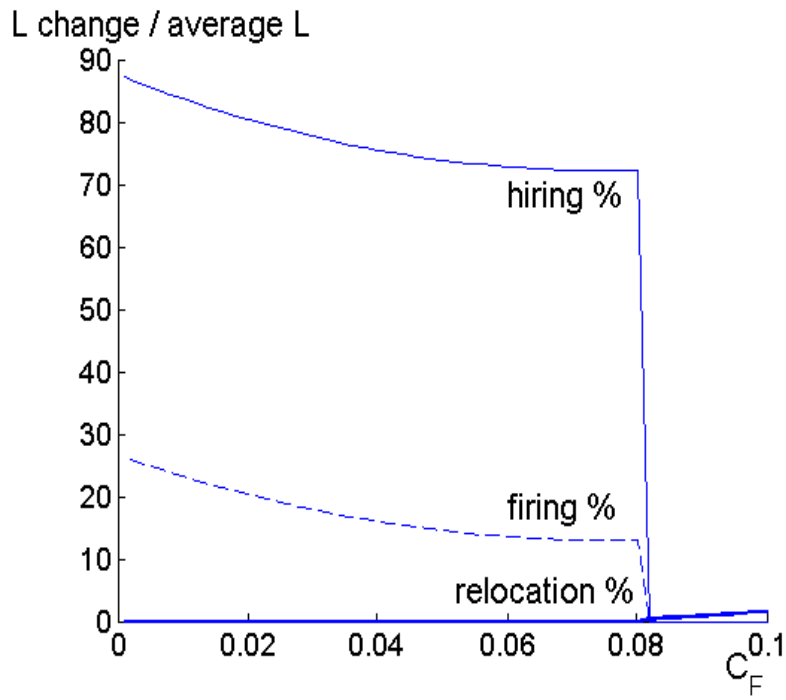

(iv) Hiring and Firing $\%$ vs. $C_{F}$

Figure 12: The effect of firm-sized firing $\operatorname{cost} C_{F}$ in the current location on optimal strategy $\left(b_{F}, \bar{u}_{F}, u_{H}, b_{H}\right)$, labor level $L$, value function $\bar{f}(\eta)$, and on hiring and firing relative to the average labor level before relocation and at the relocation time. Compare with Figure 6. The model parameters in the current and alternative locations are in Table 2, except in the alternative location firing delay $\Delta=0.01$. The relocation cost $\widehat{R}=0.1$. Figures (ii) and (iv) are calculated by Monte Carlo Simulation with initial value $\eta_{0}=0.3$ and 120 time steps over a ten year time horizon. In Figure (iv) "relocation" is firing in the current location when relocated and "firing" is firing in the current location when location is not changed. 
when $c_{F}>0.2$, there is no hiring. The elasticities are as follows:

$E_{\text {hiring, proportional firing cost }}=-1.11, \quad E_{\text {firing, proportional firing cost }}=-1.62, \quad$ and $E_{\text {relocation, proportional firing cost }}=1.09$,

i.e., the proportional firing cost decreases substantially hiring and firing before relocation and raises substantially firing due to relocation. Further, hiring and firing are more elastic in this case than under the firm-sized costs in subsection 5.3 and without the relocation option in Section 3 .

\section{Conclusions}

We have derived a new hiring and firing model that considers proportional hiring and firing costs, firing delays, firm-sized hiring and firing costs, and relocation of the production. Our model implies that the labor market frictions decrease the profitability and change substantially the hiring and firing policy of companies that have high demand or productivity uncertainty. Among the labor market frictions studied in this paper, we find that the hiring and firing policy is most sensitive to proportional hiring and firing costs and the relocation decision to firm-sized hiring and firing costs. Further, hiring and firing policies of companies that have option to relocate are more sensitive to labor market frictions than of those without the option.

The high uncertainty companies have high incentive to relocation. The relocation and the lower profitability under high uncertainty indicate that in countries and states with high labor market frictions, there are less companies with high demand or productivity uncertainty, and hence the prevalence of companies that have low demand and productivity uncertainty is higher there. Since these low uncertainty firms hire and fire less, the high prevalence of the low uncertainty firms decreases job reallocation rates in states and countries with high labor market frictions. 


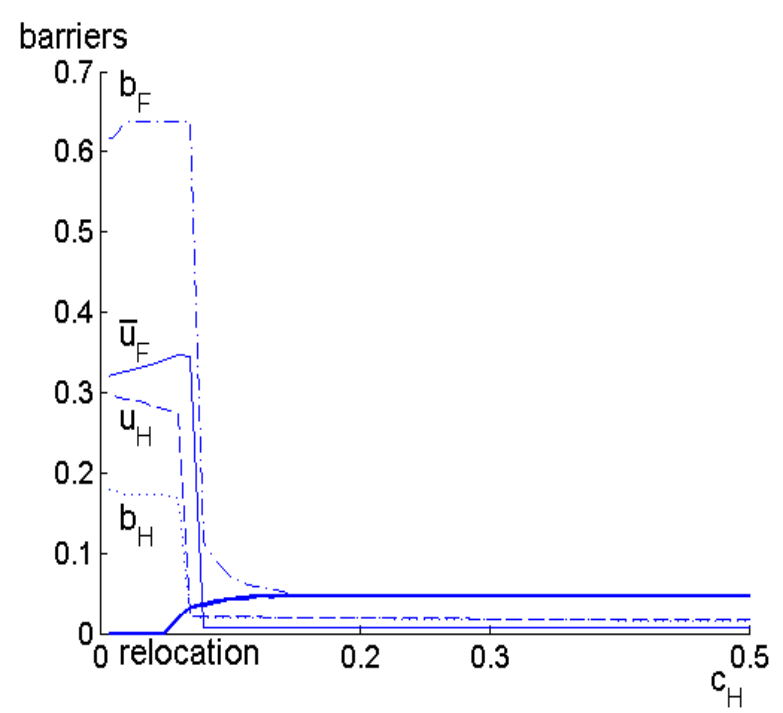

(i) Barriers vs. $c_{H}$

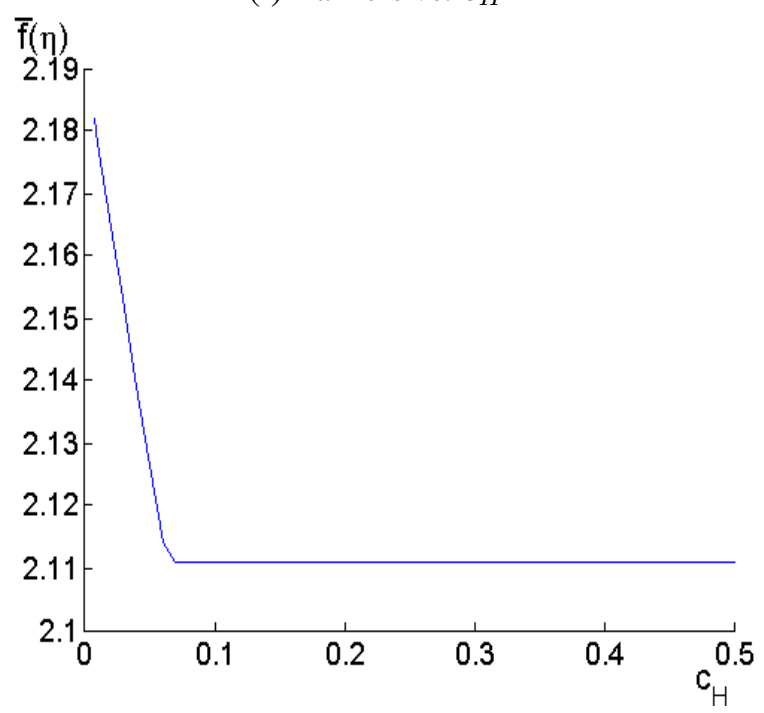

(iii) Value Function vs. $c_{H}$

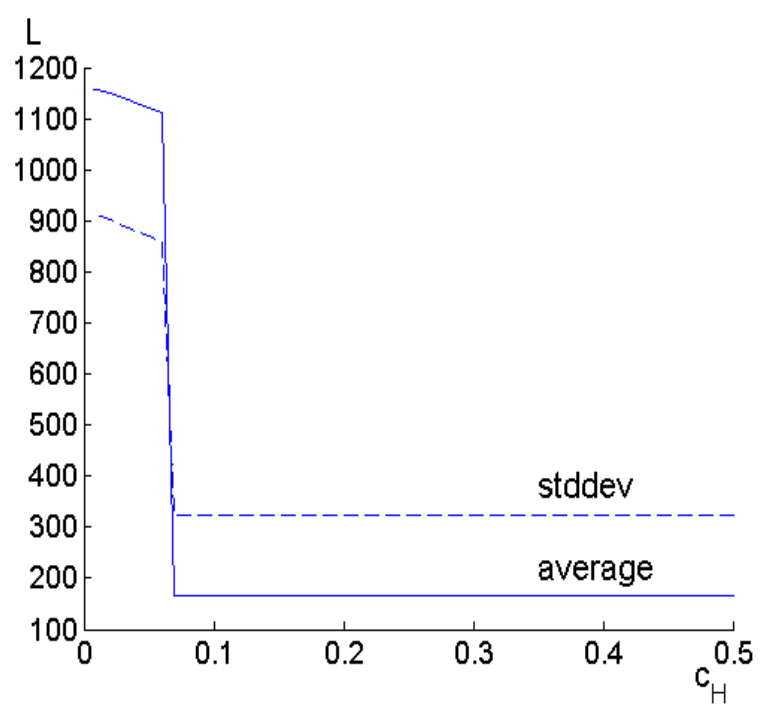

(ii) Labor Level vs. $c_{H}$

$\mathrm{L}$ change / average $\mathrm{L}$

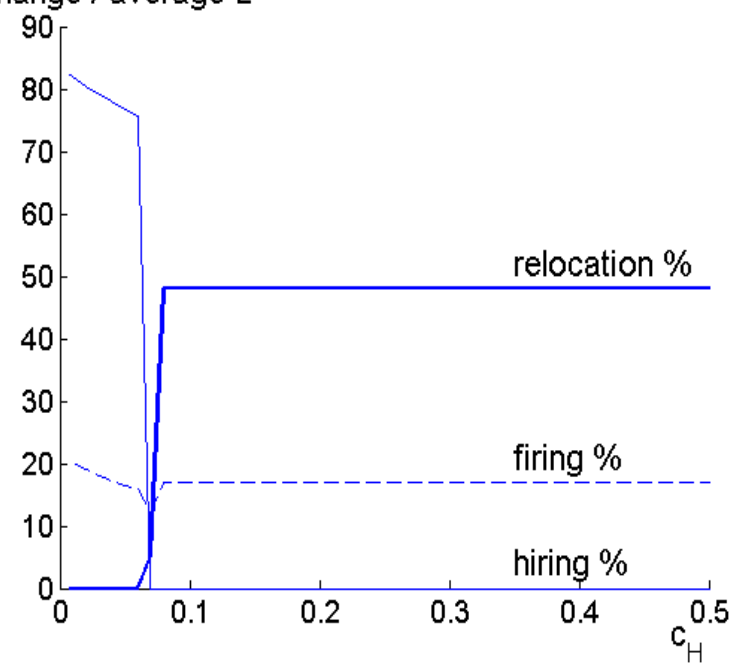

(iv) Hiring and Firing $\%$ vs. $c_{H}$

Figure 13: The effect of proportional hiring costs $c_{H}$ in the current location on optimal strategy $\left(b_{F}, \bar{u}_{F}, u_{H}, b_{H}\right)$, labor level $L$, value function $\bar{f}(\eta)$, and on hiring and firing relative to the average labor level before relocation and at the relocation time. Compare with Figure 7. The model parameters in the current and alternative locations are in Table 2, except in the alternative location firing delay $\Delta=0.01$. The relocation cost $\widehat{R}=0.1$. Figures (ii) and (iv) are calculated by Monte Carlo Simulation with initial value $\eta_{0}=0.3$ and 120 time steps over a ten year time horizon. In Figure (iv) "relocation" is firing in the current location when relocated and "firing" is firing in the current location when location is not changed. 


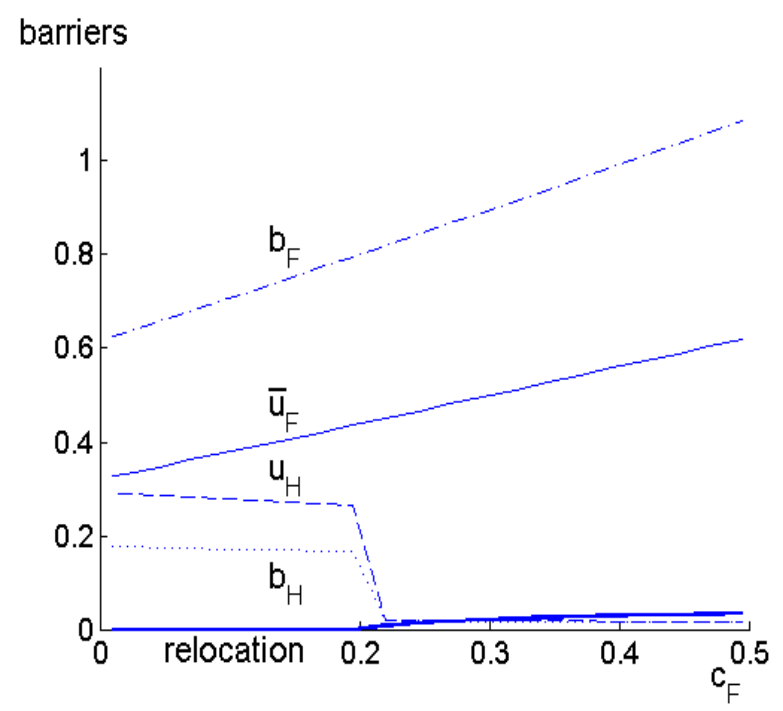

(i) Barriers vs. $c_{F}$

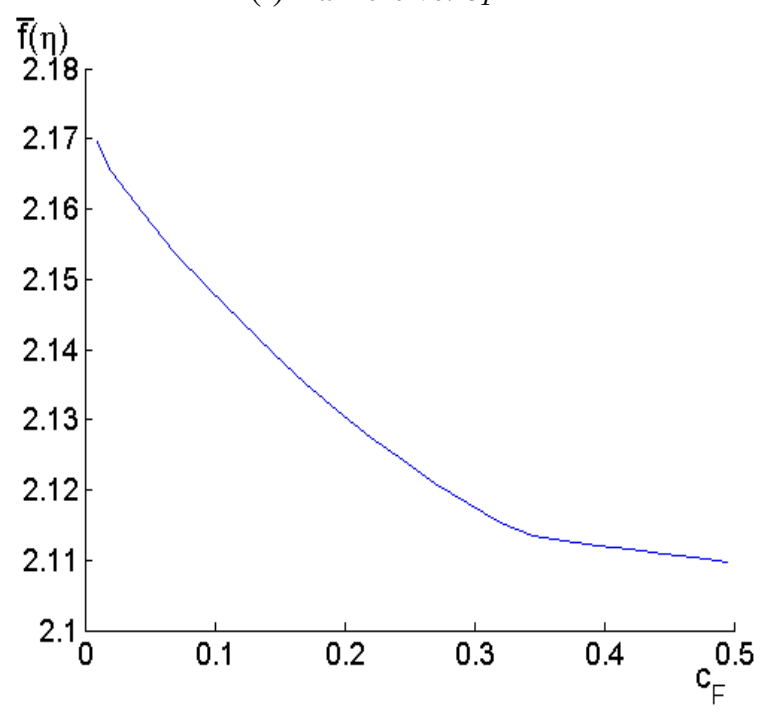

(iii) Value Function vs. $c_{F}$

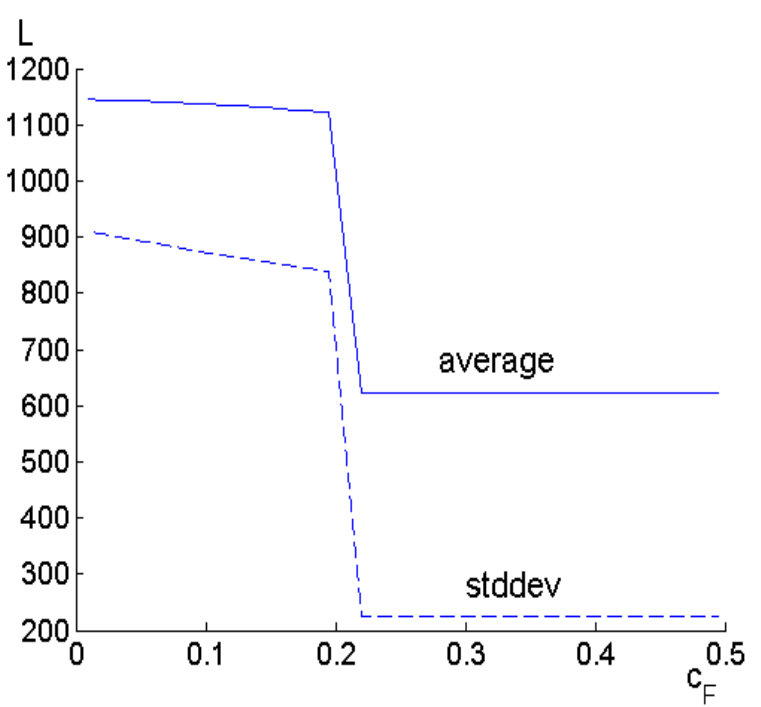

(ii) Labor Level vs. $c_{F}$

$\mathrm{L}$ change / average L

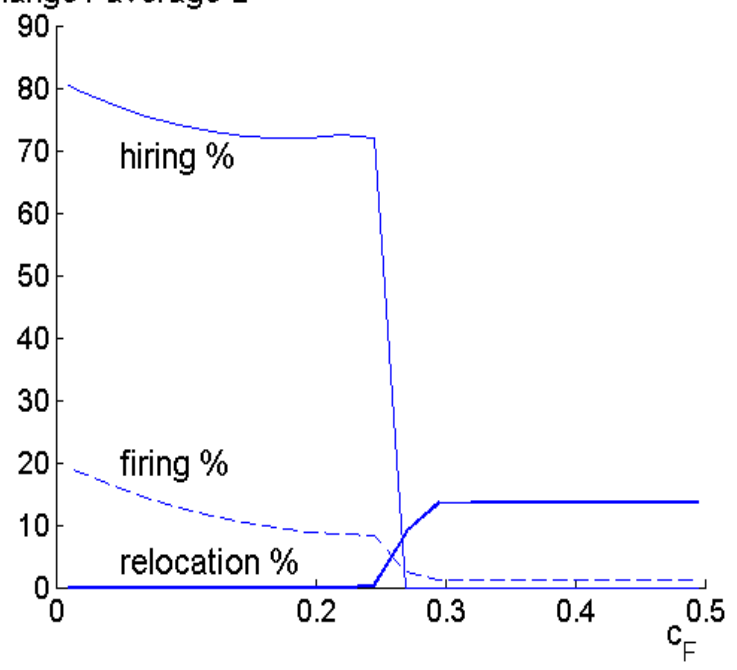

(iv) Hiring and Firing $\%$ vs. $c_{F}$

Figure 14: The effect of proportional firing $\operatorname{costs} c_{F}$ in the current location on optimal strategy $\left(b_{F}, \bar{u}_{F}, u_{H}, b_{H}\right)$, labor level $L$, value function $\bar{f}(\eta)$, and on hiring and firing relative to the average labor level before relocation and at the relocation time. Compare with Figure 8 The model parameters in the current and alternative locations are in Table 2, except in the alternative location firing delay $\Delta=0.01$. The relocation cost $\widehat{R}=0.1$. Figures (ii) and (iv) are calculated by Monte Carlo Simulation with initial value $\eta_{0}=0.3$ and 120 time steps over a ten year time horizon. In Figure (iv) "relocation" is firing in the current location when relocated and "firing" is firing in the current location when location is not changed. 


$$
\bar{h}_{2}(\eta) \leq h_{1}(\eta) \leq c_{H}^{1}
$$

so, $h_{1}(\eta)=c_{H}^{1}$, i.e., $\eta \in H R_{1}$. This indicates $H R_{2} \subset H R_{1}$, by which we infer that $b_{H}$ is decreasing in $c_{H}$. The proof is complete.

\section{References}

Acemoglu, Daron, William Hawkins. 2014. Search with multi-worker firms. Theoretical Economics, 9(3), $583-628$.

Alvarez, Luis H. R., Jussi Keppo. 2002. The impact on delivery lags on irreversible investment under uncertainty. European Journal of Operational Research, 136, 173-180.

Bentolila, Samuel, Giuseppe Bertola. 1990. Firing costs and labour demand: How bad is Eurosclerosis? Review of Economic Studies, 57(3), 381-402.

Bentolila, Samuel, Gilles Saint-Paul. 1994. A model of labor demand with linear adjustment costs. Labour Economics, 1(3-4), 303-326.

Bertola, Giuseppe. 1992. Labor turnover costs and average labor demand. Journal of Labor Economics, 10(4), 389-411.

Bertola, Giuseppe and Rogerson, Richard. 1997. Institutions and labor reallocation. European Economic Review, 41(6), 1147-1171.

Björk, Tomas. 2004. Arbitrage Theory in Continuous Time. 2nd ed. Oxford University Press.

Blanchard, Olivier, Pedro Portugal. 2001. What hides behind an unemployment rate: Comparing Portuguese and U.S. labor markets. American Economic Review, 91(1), 187-207.

Blankenship, G.L., J.-L. Menaldi. 1984. Optimal stochastic scheduling of power generation systems with scheduling delays and large cost differentials. SIAM Journal on Control and Optimization, 22(1), $121-132$.

Bloom, Nicholas. 2009. The impact of uncertainty shocks. Econometrica, 77(3), 623-685.

Caballero, Richard, Eduardo Engel, John Haltiwanger. 1997. Aggregate Employment Dynamics: Building From Microeconomic Evidence. American Economic Review, 87, 115-137. 
Chen, Yu-Fu, Dennis Snower, Gylfi Zoega. 2003. Labour-market institutions and macroeconomic shocks. Labour, 17(2), 247-270.

Cooper, Russell, Jonathan L. Willis. 2003. A Comment On The Economics Of Labor Adjustment: Mind The Gap. American Economic Review, 94, 1223-1237.

Crandall, Michael G., Hitoshi Ishii, Pierre-Louis Lions. 1992. User's Guide to Viscosity Solutions of Second Order Partial Differential Equations. Bulletin of the American Mathematical Society, 27, $1-67$.

Cunat, Alejandro, Marc J. Melitz. 2012. Volatility, Labor Market Flexibility, and the Pattern of Comparative Advantage. Journal of the European Economic Association, 10(2), 225-254.

Dai, Min, Yue Kuen Kwok, Hong You. 2007. Intensity-based framework and penalty formulation of optimal stopping problems. Journal of Economic Dynamics and Control, 31(12), 3860-3880.

Dai, Min, Fahuai Yi. 2009. Finite horizon optimal investment with transaction costs: a parabolic double obstacle problem. Journal of Differential Equations., 246, 1445-1469.

Davis, Steven J, R Jason Faberman, John Haltiwanger. 2006. The flow approach to labor markets: New data sources and micro-macro links. Working paper, University of Chicago.

Davis, Steven J, R Jason Faberman, John Haltiwanger, Ron S. Jarmin, Javier Miranda. 2010. Business Volatility, Job Destruction, and Unemployment. American Economic Journal: Macroeconomics, 2(2), 259-287.

Davis, Steven J, John Haltiwanger, Ron S. Jarmin, Javier Miranda. 2007. Volatility and Dispersion in Business Growth Rates: Publicly Traded versus Privately Held Firms. NBER Macroeconomics Annual, 2006.

Davis, Steven J, John Haltiwanger. 2014. Labor Market Fluidity and Economic Performance. Working paper, University of Chicago.

Decker, Ryan, John Haltiwanger, Ron S. Jarmin, Javier Miranda. 2014. The Secular Decline of Business Dynamics in the United States. Working paper, University of Maryland.

Duffie, Darrell. 2001. Dynamic Asset Pricing Theory. Princeton University Press.

Faia, Ester. 2008. Optimal Monetary Policy Rules with Labour Market Frictions. Journal of Economic Dynamics and Control, 32, 1600-1621.

Faia, Ester, Wolfgang Lechthaler, Christian Merkl. 2013. Fiscal stimulus and labor market policies in EuropeOriginal Research Article Journal of Economic Dynamics and Control, 37, 483-499. 
Fleming, H. Wendell, H. Mete Soner. 1993. Controlled Markov Processes and Viscosity Solutions. Springer Verlag.

Forsyth, P.A., K.R. Vetzal. 2002. Quadratic convergence for valuing American options using a penalty method. SIAM Journal on Scientific Computation, 23, 2096-2123.

Friedman, A. (1982). Variational Principles and Free-Boundary Problems. Wiley, New York.

Gustafsson, Bertil. 2011. Fundamentals of Scientific Computing. Vol. 8, Springer.

Haltiwanger, John, Stefano Scarpetta, Helena Schweiger. 2014. Cross country differences in job reallocation: The role of industry, firm size and regulations. Labour Economics, 26, 11-25.

Hamermesh, Daniel. 1989. Labor Demand and the Structure of Adjustment Costs. American Economic Review, 79, 674-689.

Højgaard, Bjarne, Michael Taksar. 1999. Controlling risk exposure and dividends payout schemes: insurance company example. Mathematical Finance, 9, 153-182.

Hopenhayn, Hugo and Rogerson, Richard. 1993. Job turnover and policy evaluation: A general equilibrium analysis. Journal of political Economy, 101(5), 915-938.

Kleiner, Morris M., Alan B. Krueger. 2013. Analyzing the Extent and Influence of Occupational Licensing on the Labor Market. Journal of Labor Economics, 31(2), 173-202.

Krause, Michael, Harald Uhlig. 2011. Transitions in the German labor market: Structure and crisis Journal of Monetary Economics, 59, 64-79.

Lloyd, Caroline. 1999. Regulating employment: Implications for skill development in the aerospace industry. European Journal of Industrial Relations, 5(2), 163-185.

Ljungqvist, Lars, Thomas J. Sargent. 1995. Welfare States and Unemployment. Economic Theory, 6, $143-160$.

Ljungqvist, Lars, Thomas J. Sargent. 2008. Two Questions about European Unemployment. Econometrica, 76, 1-29.

Lubik, Thomas A. 2012. Aggregate Labour Market Dynamics in Hong Kong. Pacific Economic Review, 17, 257-279.

Nickell, Stephen. 1997. Unemployment and labor market rigidities: Europe versus North America. Journal of Economic Perspectives, 11(3), 55-74.

OECD. 1999. OECD Employment Outlook 1999. OECD.

OECD. 2004. OECD Employment Outlook 2004. Brookings Institution Press. 
Bernt, Oksendal, Agnes Sulem. 2002. Optimal consumption and portfolio with both fixed and proportional transaction costs. SIAM Journal on Control and Optimization, 40(6), 1765-1790.

Peura, Samu, Jussi Keppo. 2006. Optimal bank capital with costly recapitalization. Journal of Business, 79(4), 2163-2201.

Robin, Maurice. 1977. Contróle impulsionnel des processus de markov. Ph.D. thesis, INRIA, Le Chesnay, France.

Siebert, Horst. 1997. Labor market rigidities: at the root of unemployment in Europe. Journal of Economic Perspectives, 11(3), 37-54.

Wilmott, Paul. 2007. Quantitative Finance. 2nd ed., John Wiley \& Sons. 